\title{
Characterisation of low-odour emissive polylactide/cellulose fibre biocomposites for car interior
}

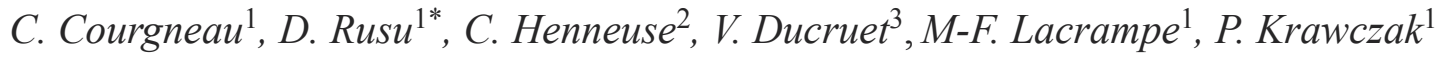 \\ ${ }^{1}$ Ecole Nationale Supérieure des Mines de Douai (Mines Douai), Department of Polymers and Composites Technology \& \\ Mechanical Engineering, 941 rue Charles Bourseul, F-59508 Douai, France \\ ${ }^{2}$ CERTECH (CEntre de Ressources TEchnologique en CHimie) ZI C, rue Jules Bordet, B-7180 Seneffe, Belgium \\ ${ }^{3}$ INRA, UMR 1145 Food Process Engineering, 1 avenue des Olympiades, F-91300 Massy, France
}

Received 10 April 2013; accepted in revised form 9 June 2013

\begin{abstract}
Low odour-emissive polylactide/cellulose fibre biocomposites, intended for car interior, were prepared and characterised. The impact of the different stages of processing (drying cycles, compounding, injection moulding) on the extent of polylactide degradation and on biocomposites properties was investigated by size exclusion chromatography, thermogravimetry, differential scanning calorimetry. In parallel, the odour emission of these materials was quantified via dynamic dilution olfactometry and Field of odours ${ }^{\circledR}$ method. The changes in molecular weight and global odour emission indicated that compounding had a strong impact on polylactide degradation and odour emission, while injection moulding had no significant impact. Adding $0.5 \mathrm{wt} \%$ of an absorbent agent based on poly(1-methylpyrrol-2-ylsquaraine could) divide the global odour concentration by a factor 2 . The morphology, mechanical and thermal properties of injection moulded PLAbiocomposites were not affected by the presence of the absorbent agent.
\end{abstract}

Keywords: biocomposites, polylactide, cellulose fibres, odour emission, absorbent particles

\section{Introduction}

These last two decades, eco-friendly composites based on natural fibres and bio-based polymers have been considered as very attractive materials for automotive parts. Indeed, subjected to regulations which impose that by $2015,85 \%$ of vehicle components must be reused or recycled [1], Original Equipment Manufacturers (OEMs) have to provide sustainability efforts, while meeting very demanding requirements, such as high thermomechanical performance at both very short and very long terms $[2,3]$.

A wide range of environmentally friendly compostable polymers is actually available for automotive parts manufacturers, such as PLA, polybuty- lene succinate or thermoplastic starch. Among them, the thermoplastic polyester PLA has a great potential to substitute petroleum-based polymers because of its high mechanical strength and modulus, its availability in large volume and suitability as matrix for the embedding of fibres in composites. This polymer is semi-crystalline, depending on its stereochemistry and processing conditions [4-7], and suitable for a wide range of industrial processing technologies, as injection moulding, blow-moulding, thermoforming, cast film and others [8]. However, in spite of promising properties, the bio-based plastics rarely meet the very demanding requirements of automotive industry [9]. Consequently, solutions are investigated, such as fibre reinforcement, to improve their mechanical performance.

\footnotetext{
${ }^{*}$ Corresponding author, e-mail: daniela.rusu@mines-douai.fr (C) BME-PT
} 
Many types of fibres, natural (wood, flax, hemp, kenaf...) or synthetic (glass, carbon, aramide), were associated to petroleum-based polymers and more recently to bio-based plastics [10-16].

The vegetal fibres are an interesting eco-friendly reinforcement system, as they are annually renewable, lighter, cheaper and less reliant on foreign oil sources than synthetic fibres [17]. In addition, their specific mechanical properties are close to those of glass fibres, widely used in automotive industry [2, 17, 18]. Moreover, using natural fibres to reinforce polymers matrix instead of glass fibres would make it possible to reduce the weight of composite structures, and finally the overall weight of the car. The vegetal fibres also demonstrate environmental benefits compared to glass fibres, such as ecological sustainability, low energy requirements for production, and carbon dioxide neutrality [19]. However, they have also some drawbacks such as moisture uptake, quality variation, low thermal stability, emission of volatile organic compounds (VOCs) and fogging generation [20,21]. These sensorial defects are often assigned to the degradation of lignin, one of the major components of natural fibres among cellulose, hemicellulose, waxes and other watersoluble compounds. Actually, contrary to cellulose, which degrades above $300^{\circ} \mathrm{C}$, lignin and hemicellulose are less thermo-resistant and start to degrade from $200^{\circ} \mathrm{C}$ [22], and even from $170^{\circ} \mathrm{C}$ [23] as demonstrated for flax and jute fibres. This is an issue to be considered for melt processing, as these onset decomposition temperatures fall within the typical range of processing temperatures of numerous thermoplastic polymers.

Each type of natural fibres has a specific chemical composition and so, distinct mechanical and physical properties that tune differently the biocomposites properties in which they are incorporated. Yet, almost all automotive manufacturers are already using natural fibres-reinforced petro-polymers for different car parts, i.e. seat backs, side and back doorpanels, boot liners [17, 19, 24]. In the case of PLA, a wide range of vegetal fibres (flax [25, 26], kenaf [27], hemp [28], wood flour or pulp [29, 30]) was used in order to adapt the properties of PLA-biocomposites to the technical specifications for automotive applications. Generally, the mechanical properties of the matrix are greatly improved by incorporating natural fibres, whatever their type [29, 31-34]. Nevertheless, the reinforcement efficiency depends on the processing technique used to incorporate the fibres, on fibre content, as well as on the fibre orientation and aspect ratio.

Usually, the choice of the fibres for a specific automotive application depends on the balance between the cost and (local) availability, weight, mechanical features and possible issues related to the odour emission [35, 36]. This last aspect is particularly important for confined-space applications, such as cars interior, where the VOCs and odour emitted by a large variety of chemicals form the 'New Smell' of car cabins, which can lead in some cases to the 'Sick Car Syndrome'.

However, to our best knowledge, few reports are available on the reduction of the odour and VOC concentrations in small confined-spaces, despite the increasing use of biocomposites in car interior parts. Two different approaches were used by Kim and coworkers [37-39], i.e., devolatilization of VOCs by baking-out process or adding inorganic fillers. In such works, PLA degradation and mechanical performance of PLA parts were not considered.

In this context, the present study aims to prepare low odour-emissive PLA-biocomposites with interesting thermal and mechanical properties intended for car interior parts. To limit the odour emission of biocomposites, cellulose-based fibres $(99.5 \%$ cellulose) were chosen to reinforce the PLA, and a recent commercially available porous system, based on poly(1-methylpyrrol-2-ylsquaraine) (PMPS), was used as potential absorbent agent.

The odour emission was examined after each processing stage of the biocomposite parts (with and without absorbent agent) and compared to neat PLA parts manufactured in similar conditions (drying, compounding and injection moulding). In addition, a comparative study of the morphology, mechanical and thermal properties of PLA and PLA-biocomposites with and without absorbent agent was also carried out.

\section{Experimental \\ 2.1. Materials}

PLA pellets (PLA 4032D, NatureWorks ${ }^{\circledR}$, Minnetonka, USA) contain about $2 \%$ of D-PLA. Highly pure cellulose fibres (ca. 99.5\% cellulose) were used as reinforcing fillers (BC200, Arbocel ${ }^{\circledR}$, J. Rettenmaier \& Söhne GMBH \& Co, Rosenberg, Germany). These ribbon-like fibres have an average length and thickness of 300 and $20 \mu \mathrm{m}$ respectively. The 
absorbent agent for VOCs $(\mu-\mathrm{Sq}$ beads, Exilica Limited, Coventry, United Kingdom) is based on poly(1-methylpyrrol-2-ylsquaraine (PMPS). These particles (average diameter $\bar{\phi}=1.92 \mu \mathrm{m}$ ) are expected to absorb chemical entities due to their internal amorphous porous network.

\subsection{Preparation of biocomposites samples: Compounding and injection moulding}

Figure 1 presents schematically the entire processing cycle. Prior to processing, the PLA pellets and the absorbent agent powder were dried at $80^{\circ} \mathrm{C}$ for $22 \mathrm{~h}$ in a vacuum oven (Vacucell VU111, Avantec, Illkirch, France), to remove the moisture. The cellulose fibres were dried at $115^{\circ} \mathrm{C}$ for $24 \mathrm{~h}$, in a standard oven (SR2000, Thermosi, France). PLA-biocomposites with $10 \mathrm{wt} \%$ of cellulose fibres were prepared using a twin-screw extruder (BC45, Clextral, Firminy, France), equipped with screws having $L / D$ ratio of 25 and diameter of $50 \mathrm{~mm}$. In the case of PLA-biocomposites with $10 \mathrm{wt} \%$ cellulose fibres (8.4 vol\%) and $0.5 \mathrm{wt} \%$ absorbent agent, a dry blending of the cellulose and absorbent powder was first performed, and then the blend was incorporated into the PLA by melt processing, as described above. In all cases, the temperature profile ( 6 zones) along the extruder, from hopper to die end, was maintained as $170-170-170-170-180-180^{\circ} \mathrm{C}$, for a screws speed of $110 \mathrm{rpm}$. The residence time in extruder was of about 6-7 min. Neat PLA samples were extruded in the same conditions, for comparison purpose. The extrudates were cooled through a $0.8 \mathrm{~m}$ long water-bath, then granulated and submit- ted to a second drying cycle under vacuum at $45^{\circ} \mathrm{C}$ for the first $15 \mathrm{~h}$, and then at $80^{\circ} \mathrm{C}$ for $72 \mathrm{~h}$. Once dried, the pellets of compounded neat PLA and PLAbiocomposites were injection moulded in bars and dumbbell-shaped specimens by using an injection moulding machine (KM80-160E, Krauss-Maffei, Munich, Germany). The injection moulding temperature was kept constant at $180^{\circ} \mathrm{C}$ and the injection moulding flow rate was set at $63 \mathrm{~cm}^{3} / \mathrm{s}$. The holding stage was carried out in three steps of $15 \mathrm{~s}$, at 950,750 and 500 bars. The mould temperature was kept at $30^{\circ} \mathrm{C}$.

The samples are denoted as PLA for neat PLA, PLA10F for PLA-biocomposite with $10 \mathrm{wt} \%$ of cellulose fibre, and PLA10F05Ex for biocomposite with $0.5 \mathrm{wt} \%$ of absorbent agent. The codes $-\mathrm{C}$ and $-\mathrm{CI}$ added to the sample names stand for compounded samples and compounded/injection moulded samples, respectively. The codes $d$ and nd indicate whatever the sample under study is dried or not.

\subsection{Characterization methods}

\subsubsection{Moisture analysis}

Moisture content of raw materials and intermediary products was determined by Karl-Fisher method, with a Karl-Fisher volumetric titrator (V30, Mettler Toledo, France). The samples were heated to $150^{\circ} \mathrm{C}$ for $30 \mathrm{~min}$ under dried nitrogen gas flow of $40 \mathrm{~mL} / \mathrm{min}$ within the drying oven. The concentration of the reagent was determined with sodium tartrate dihydrate. Three replicates were analyzed for raw materials and intermediate products.

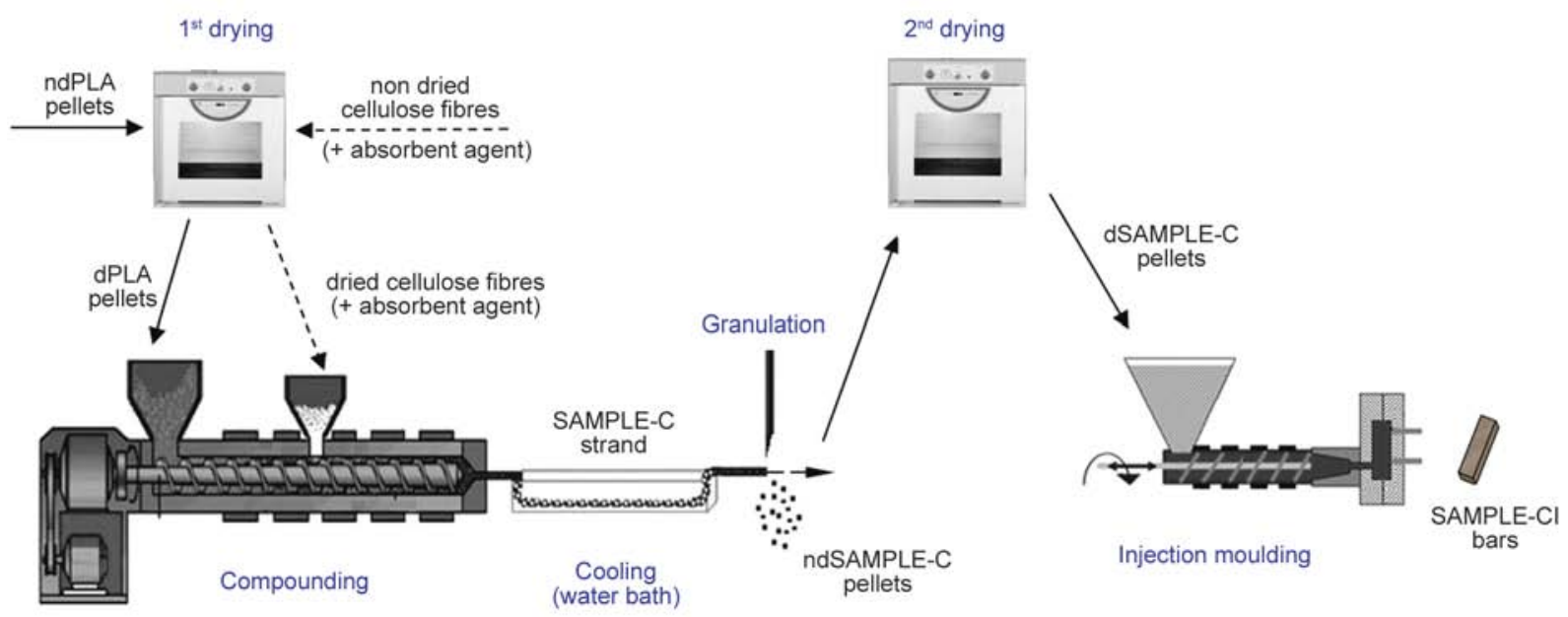

Figure 1. Schematic representation of different processing steps to obtain injection moulded parts. In this work, SAMPLE means either neat PLA or PLA-biocomposites without or with absorbent agent (PLA10F and PLA10F05Ex, respectively) 


\subsubsection{Fibre content of PLA-biocomposites}

PLA-biocomposite pellets were dissolved in chloroform $(5 \mathrm{~g}$ in $200 \mathrm{~mL})$ for $90 \mathrm{~min}$. The suspension was then filtered over a Büchner funnel equipped with a paper filter (Macherey-Nagel GmbH \& Co. $\mathrm{KG}$, Düren, Germany) with pore size $4-12 \mu \mathrm{m}$, to remove the cellulose fibres and, respectively, the cellulose fibres/absorbent agent particles and to collect them. Once washed with chloroform, the residue was dried in oven (BM 40, Memmert, Germany) at $70^{\circ} \mathrm{C}$ for $24 \mathrm{~h}$, until constant weight. The solid residue was weighted to calculate the fibre and fibre/absorbent agent content in PLA-biocomposites. Three replicate tests were done for PLA and PLA-biocomposite pellets.

\subsubsection{Scanning electron microscopy (SEM)}

SEM micrographs were made from cryo-fractured surfaces of injection moulded bars from PLA-biocomposites and neat PLA samples. The biocomposites morphology, the dispersion effectiveness and the adhesion quality between cellulose fibres and respectively absorbent agent and the PLA matrix were investigated using a scanning electron microscope (S-4300SE/N, Hitachi, Tokyo, Japan) with field emission gun and accelerating voltage of $15 \mathrm{kV}$. Prior to observation, the fracture surfaces were coated with a thin gold layer, using a sputter coater (SEM Coating System, Polaron, Watford, United Kingdom).

\subsubsection{Melt flow index (MFI)}

PLA and biocomposite pellets were dried at $80^{\circ} \mathrm{C}$ for $22 \mathrm{~h}$, in a vacuum oven (Vacucell 111VU111, Avantec, Illkirch, France), prior to melt flow index measurements. The MFI experiments were performed on a MFI apparatus (NG-M, Göttfert, Buren, Germany) at $190^{\circ} \mathrm{C}$ and $2.16 \mathrm{~kg}$ mass, according to NF T 51-016 standard. After a pre-heating period of $240 \mathrm{~s}$, samples were collected every $30 \mathrm{~s}$. The MFI was calculated as an average of 20 values and expressed in $\mathrm{g} / 10 \mathrm{~min}$.

\subsubsection{Size exclusion chromatography (SEC)}

The average molecular weights $\left(\bar{M}_{\mathrm{n}}, \bar{M}_{\mathrm{w}}\right)$ and polydispersity index $\left(\nexists=\bar{M}_{\mathrm{w}} / \bar{M}_{\mathrm{n}}\right)$ of PLA were determined at room temperature by size exclusion chromatography in chloroform. In the case of biocomposites, the cellulose fibres were first extracted and the SEC measurements were performed on diluted
PLA solutions obtained from filtrates. The SEC system consisted of a HPLC pump (Waters Alliance 2690 Separation Module, Waters Corp., Milford, Massachusetts, USA) and a differential refractometer (Waters 2414 Refractive Index Detector, Waters Corp., Milford, Massachusetts, USA). The flow rate was $1 \mathrm{~mL} / \mathrm{min}$. A set of columns (Waters Styragel HR4E and HR5E, Waters Corp., Milford, Massachusetts, USA) covering the molecular weight range between 100 and $4000000 \mathrm{~g} / \mathrm{mol}$ was used. Calibration was performed using narrow distributed polystyrene standards and the sample chromatograms were processed with SEC-Waters software.

\subsubsection{Thermo-gravimetric analysis (TGA)}

The thermal stability of samples was determined with a thermogravimetric analyzer (Q500 TGA, TA Instruments, New Castle, USA). The tests were performed on 5-10 mg samples from 30 to $580^{\circ} \mathrm{C}$ with Hi-Res dynamic mode at $10^{\circ} \mathrm{C} / \mathrm{min}$ (sensitivity 1.0 , resolution 4.0) under a nitrogen purge. The percent weight loss and derivative weight loss were plotted against temperature in order to evaluate $T_{5 \%}, T_{50 \%}$, $T_{95 \%}$ and $T_{\max }$, defined as temperatures at which 5 , 50 and $95 \%$ of the total mass is volatilized, and respectively the temperature of the maximum rate of weight loss of the PLA samples. Three replicates were scanned for the PLA pellets as received and after drying, as well as for each neat PLA and biocomposite sample.

\subsubsection{Differential scanning calorimetry (DSC)}

The thermal behaviour of the PLA raw material, processed neat PLA and PLA-biocomposites were examined with a differential scanning calorimeter (DSC 8500, Perkin-Elmer, Waltham, USA) equipped with a Dewar tank (CryoFill, Perkin-Elmer, Waltham, USA). Indium was used as standard calibration material. The samples (ca. $8 \mathrm{mg}$ ) were heated from 0 to $190^{\circ} \mathrm{C}$, with a heating rate of $10^{\circ} \mathrm{C} / \mathrm{min}$, under nitrogen flow. The glass transition temperature was taken as the midpoint of the heat capacity change. The cold crystallization and melting temperatures and heats were determined from the maxima and areas of the crystallization and melting peaks, respectively. The crystallinity degree $\left(\chi_{\mathrm{c}}\right)$ was calculated according to Equation (1):

$$
\chi_{\mathrm{c}}=\frac{\Delta H_{\mathrm{m}}-\Delta H_{\mathrm{cc}}}{\Delta H_{\mathrm{m}}^{100 \%}} \cdot \frac{100}{1-\omega_{\mathrm{f}}}
$$


where $\Delta H_{\mathrm{m}}$ and $\Delta H_{\mathrm{cc}}$ are the heat of melting and cold crystallization of the PLA and biocomposites, $\Delta H_{\mathrm{m}}^{100 \%}$ is the heat of melting for $100 \%$ crystalline PLA (93 J/g) [40] and $\omega \mathrm{f}$ is the content of fibre and absorbent agent in PLA-biocomposites.

\subsubsection{Mechanical properties}

The uniaxial tensile tests were performed on dumbbell-shaped specimens according to ISO 527-2, at room temperature, using a standard testing machine (LR 50K, Lloyd, Bognor Regis, United Kingdom) with a load cell of $5 \mathrm{kN}$. A crosshead speed of $10 \mathrm{~mm} / \mathrm{min}$ was used for measuring the strength and elongation at break, and the tensile strength at yield. The Young moduli were measured with an extensometer (Model 2620-602, Instron, USA), at $1 \mathrm{~mm} / \mathrm{min}$. The Charpy unnotched impact strengths were measured on injection moulded bar specimens with dimensions $80 \times 10 \times 4 \mathrm{~mm}^{3}$, using a impact tester (D7900, Zwick GmbH \& Co. KG, Ulm, Germany) equipped with an impact hammer of $7.5 \mathrm{~J}$. At least 10 specimens were tested for each injection moulded biocomposite and neat PLA, after conditioning at $23^{\circ} \mathrm{C}(50 \% \mathrm{RH})$ for one week at least.

\subsubsection{Global odour analysis}

In order to analyze the impact of each processing stage on the global odour of neat PLA and PLAbiocomposites, samples were collected in glass bottles as following:

- before compounding:dried raw materials (dPLA pellets and cellulose fibres);

- after compounding/granulation/2 ${ }^{\text {nd }}$ drying: dried pellets of compounded PLA and PLA-biocomposites (dPLA, dPLA10F-C and dPLA10F05Ex-C, respectively);

- after compounding/granulation/2 $2^{\text {nd }}$ drying and injection moulding: bars of PLA-CI, PLA10F-CI and PLA10F05Ex-CI.

Two types of sensory analyses were performed: odour description by means of the 'Champ des Odeurs ${ }^{\circledR}$, method, and odour measurements by dynamic dilution olfactometry.

The 'Champ des Odeurs ${ }^{\circledR}$ ' (Field of odours) method [41] was applied by six trained experts, who described qualitatively and quantitatively the global odour emitted by PLA, cellulose fibres and PLA-biocomposites. The analyses were performed according to ISO5496, on a series of samples of about $100 \mathrm{~g}$ placed in $10 \mathrm{~L}$ sampling bags (Tedlar ${ }^{\circledR}$ polyvinyl fluoride bags, DuPont ${ }^{\mathrm{TM}}$, Chapel Hill, USA) with pure air, and preconditioned for 2 hours at $90^{\circ} \mathrm{C}$. More than 45 descriptors (reference molecules diluted in alcohol) are used to characterise the odours and can be seen as the alphabet used to analyse and describe odours. These analyses involve basically experts, also named panellists (10 people). They gather together at least once a week for one or two hours training and working session. During each session, their individual recognition scores are tested and monitored in order to obtain individual and panel recognition scores.

The second approach consists on measuring the odour concentration emitted by materials, by means of dynamic dilution olfactometry, which is a standardized method (EN13725) commonly used for quantifying odours. The analyses were performed on a set of samples of about $400 \mathrm{~g}$ placed in $40 \mathrm{~L}$ Tedlar ${ }^{\mathbb{R}}$ sampling bags with pure air, with the same loading factor $(10 \mathrm{~g} / \mathrm{L})$ and preconditioning $\left(90^{\circ} \mathrm{C}\right.$ for 2 hours) as for the Field of odours ${ }^{\circledR}$ method. A dilution olfactometer presented then a series of odour samples diluted with pure air at precise ratios, to a panel of six panellists, representative of the population. The dilution factor necessary to reach the odour threshold for a given sample (i.e., the minimum concentration perceived by $50 \%$ of panellists) represents the odour concentration of that sample and is expressed as $\mathrm{ou}_{\mathrm{E}} \cdot \mathrm{m}^{-3}$. The reference gas used for evaluating the sensory perception threshold is nbutanol.

\section{Results and discussion}

\subsection{Moisture content}

The moisture content of PLA materials was measured before/after each processing stage. The results are presented in Table 1. The drying protocol appeared to be effective on PLA and PLA-biocomposites. For instance, the residual water content of neat dPLA and APLA-C approached the recommended value from the PLA producer (i.e. $250 \mathrm{ppm}$ ), while in presence of $10 \mathrm{wt} \%$ of dried cellulose fibre, the moisture content was reduced to 480 $640 \mathrm{ppm}$.

\subsection{Cellulose fibre content}

The extraction of cellulose fibres by dissolution in chloroform indicates the cellulose fibres content in PLA based biocomposite: ca. 9.7\% in PLA-biocomposite and $10.9 \%$ in PLA/fibre/absorbent agent bio- 
Table 1. Moisture and solid content, number $\left(M_{\mathrm{n}}\right)$ and weight $\left(M_{\mathrm{w}}\right)$ average molecular weight, polydispersity index $(\nexists)$ and melt flow index (MFI) of PLA and PLA-biocomposites, at different moments of the processing cycle

\begin{tabular}{|c|c|c|c|c|c|c|}
\hline Sample codes & $\begin{array}{c}\text { Moisture content } \\
{[\text { ppm] }}\end{array}$ & $\begin{array}{l}\text { Solid content }^{*} \\
{[\%]}\end{array}$ & $\begin{array}{c}\mathbf{M}_{\mathrm{n}} \\
{[\mathrm{g} / \mathrm{mol}]}\end{array}$ & $\begin{array}{c}\mathbf{M}_{\mathrm{w}} \\
{[\mathrm{g} / \mathrm{mol}]}\end{array}$ & Đ & $\begin{array}{c}\text { MFI } \\
{[\mathrm{g} / \mathbf{1 0} \mathrm{min}]}\end{array}$ \\
\hline \multicolumn{7}{|c|}{ Samples based on neat PLA } \\
\hline ndPLA pellets & 3600 & ND. & 108500 & 236000 & 2.2 & $8.2 \pm 1.5$ \\
\hline dPLA pellets & 270 & ND. & 112500 & 234000 & 2.1 & $3.8 \pm 0.3$ \\
\hline ndPLA-C pellets & 2110 & ND. & 105000 & 219500 & 2.1 & ND. \\
\hline dPLA-C pellets & 260 & $0.1 \pm 0.1$ & 94000 & 205500 & 2.2 & $5.8 \pm 0.3$ \\
\hline PLA-CI bars & ND. & ND. & 90000 & 203000 & 2.3 & ND. \\
\hline \multicolumn{7}{|c|}{ Samples based on PLA-biocomposites (PLA $+10 \mathrm{wt} \%$ cellulose fibres) } \\
\hline ndPLA10F-C pellets & 5720 & ND. & 93500 & 192500 & 2.1 & ND. \\
\hline dPLA10F-C pellets & 640 & $9.7 \pm 0.5$ & 87000 & 176500 & 2.0 & $6.2 \pm 0.3$ \\
\hline PLA10F-CI bars & ND. & ND. & 81000 & 171500 & 2.1 & ND. \\
\hline \multicolumn{7}{|c|}{$\begin{array}{l}\text { Samples based on PLA-biocomposites with an odour remediation agent } \\
\text { (PLA }+10 \mathrm{wt} \% \text { cellulose fibres }+0.5 \mathrm{wt} \% \text { absorbent agent) }\end{array}$} \\
\hline ndPLA10F05Ex-C pellets & 3240 & ND. & 96000 & 188000 & 2.0 & ND. \\
\hline dPLA10F05Ex-C pellets & 480 & $10.9 \pm 0.2$ & 81500 & 174500 & 2.1 & $5.8 \pm 0.2$ \\
\hline PLA10F05Ex-CI bars & ND. & ND. & 75500 & 165000 & 2.2 & ND. \\
\hline
\end{tabular}

${ }^{*}$ cellulose fibres or cellulose fibres + absorbent agent

$\mathrm{nd}=$ non dried (sample); $\mathrm{d}=$ dried (sample)

$-\mathrm{C}=$ after compounding; $-\mathrm{CI}=$ after compounding/injection moulding cycle

ND. $=$ non determined

composites containing $0.5 \%$ absorbent particles. These observations confirm that the feeding system worked properly with low-density materials. Secondly, the good repeatability over three replicates

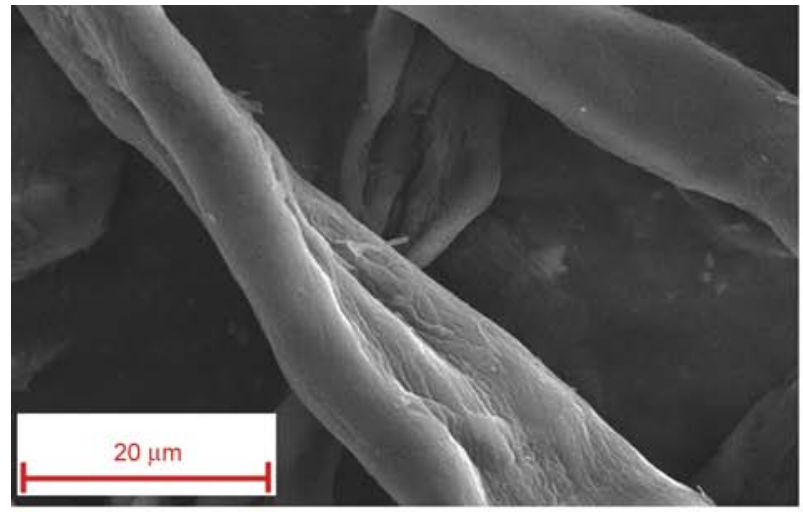

a)

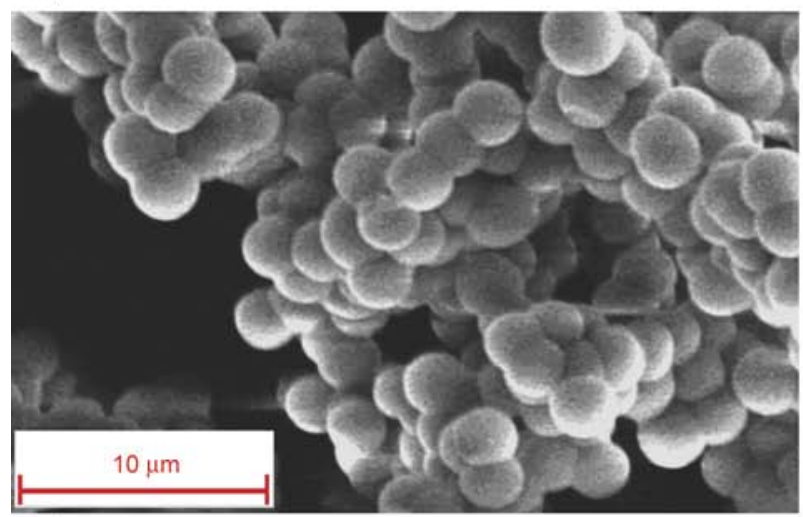

c) taken at different compounding times suggests that the cellulose fibres and absorbent particles were macroscopically homogeneously dispersed in the PLA matrix.

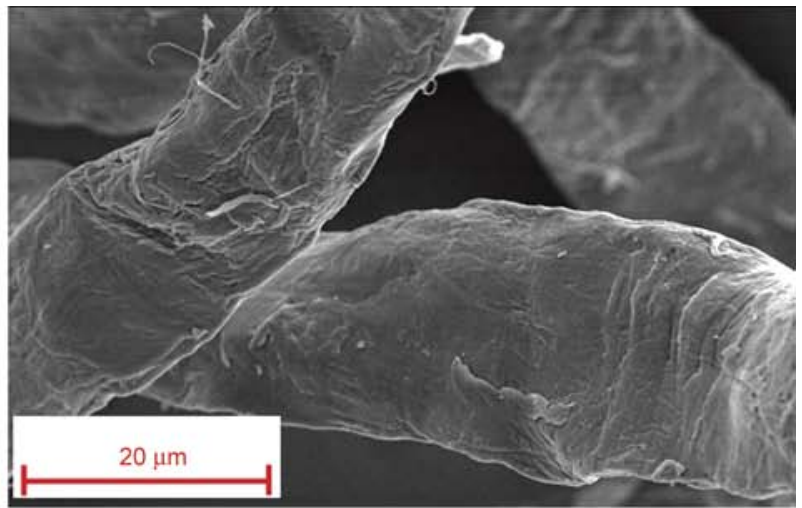

b)

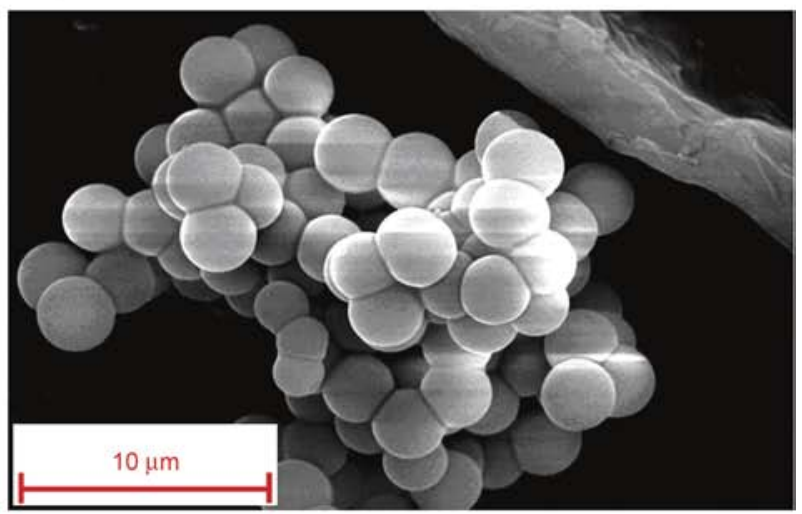

d)

Figure 2. SEM micrographs of cellulose fibres $(a, b)$ and particles of absorbent agent $(c, d)$ before and after drying 


\subsection{Morphology of PLA-biocomposites}

Figure 2 displays the SEM micrographs of cellulose fibres and absorbent particles, before and after drying stage. The cellulose fibres present a rather smooth surface (Figure 2a, 2b). The absorbent spherical particles, which form large agglomerates up to 40 $50 \mu \mathrm{m}$, keep the same organization and their structure appears unaffected by the drying process (Figure $2 \mathrm{c}$ and $2 \mathrm{~d}$ ).

Analysis of the micrographs of cryo-fractured surfaces of injection moulded neat PLA shows neither crazes nor fibrils, confirming the brittle fracture of the well-frozen structures (Figure $3 a$ and $3 b$ ).

Figure $3 \mathrm{c}$ and $3 \mathrm{~d}$ reveal a good dispersion of individual cellulose fibres in PLA matrix and confirm the effectiveness of the compounding stage.

The cryo-fractured surfaces of biocomposites display voids and interfacial debonding between cellulose fibres and PLA matrix, as well as fibre pull-out effects (Figures 3d, 3e, 3f, 3g). These observations indicate a poor adhesion between most of the fibres and the PLA matrix, despite the possible hydrogen bonds that might be formed between the slightly polar oxygen of PLA and the hydroxyl groups of cellulose [32, 42]. Similar behaviour had been reported by Huda et al. [43] for PLA-biocomposites at $30 \mathrm{wt} \%$ of vegetable fibres with a minimum of $75 \%$ of cellulose.

In the case of PLA-biocomposites with $0.5 \mathrm{wt} \%$ absorbent particles, SEM micrographs obtained at $500 \times$ to $2000 \times$ magnification (examples in Figure $3 \mathrm{f}$ and $3 \mathrm{~g}$ ) indicate the absence of large agglomerates of absorbent agent inside the polymer matrix. At higher magnifications (i.e., 5000× - Figure 3h), micro-agglomerates of absorbent agent (with less than ten particles) can be seen homogeneously distributed inside the matrix. This means that the compounding step is effective in breaking the initial large agglomerates of absorbent agent into smaller micro-agglomerates, and well dispersing them in the PLA matrix. On the other hand, voids are visible around absorbent particles, which indicate a rather poor adhesion to the PLA matrix.

\subsection{MFI}

Table 1 lists the MFI values for virgin PLA pellets before and after drying, and for dried pellets of neat PLA and PLA-biocomposites after compounding. The MFI of the non dried (as received) PLA pellets $(8.2 \mathrm{~g} / 10 \mathrm{~min})$ is much higher as compared with the dried pellets ( $3.8 \mathrm{~g} / 10 \mathrm{~min})$, because of the hydrolysis of polyester chains during the pre-heating stage at high temperature $\left(190^{\circ} \mathrm{C}\right.$ for $\left.240 \mathrm{~s}\right)$, in presence of moisture $(0.36 \%)$. The MFI of dried PLA pellets obtained by compounding at $190^{\circ} \mathrm{C}$ for $6 \mathrm{~min}$, and granulation (MFI $\mathrm{IPLA}_{\mathrm{dP}}$ ) is higher than for initial dried pellets $\left(\mathrm{MFI}_{\mathrm{dPLA}}\right)$, which corresponds to a decrease in the melt viscosity of compounded PLA, indicating a decrease in its molecular weight. This suggests that the compounding stage induced some random chain scission in PLA, most probably by a thermo-mechanical mechanism, since no water molecules were present to favour polyester hydrolysis. Van den Oever et al. [44] found similar tendency for dried PLA with 4-8\% of D-lactide compounded at $175^{\circ} \mathrm{C}$ for $15 \mathrm{~min}$ in a batch kneader. Unexpectedly, the MFI of dried pellets of PLA-biocomposites obtained after compounding/granulation $\left(\mathrm{MFI}_{\mathrm{dPLA} 10 \mathrm{~F}-\mathrm{C}}\right)$ is close to MFI $\mathrm{MPLA}_{\mathrm{dP}}$. Indeed, adding $10 \mathrm{wt} \%$ of dried cellulose fibres in PLA was expected to increase the material viscosity, and so, to decrease the MFI value as shown for ramie, flax or cotton fibres in PLA [44]. It seems that in the present case, the increase in viscosity due to the presence of short cellulose fibres is compensated by the decrease due to the reduction in molecular weight of PLA, because of degradation.

The addition of fine powder $(0.5 \mathrm{wt} \%)$ of absorbent agent does not change the MFI value of the dried PLAbiocomposites after compounding $\left(\mathrm{MFI}_{\mathrm{dPLA} 10 \mathrm{~F} 05 \mathrm{Ex}-\mathrm{C}} \approx\right.$ $\mathrm{MFI}_{\mathrm{dPLA10F-C}}$ ), which means that this absorbent agent plays no particular role in the degradation mechanism of PLA, neither to prevent nor to enhance the chain scission.

\subsection{Molecular weight}

The SEC results are presented in Table 1. The molecular weight variations of $5-10 \%$ were in our range of experimental error of SEC, however, some tendencies can be identified.

First, one can see that the drying stage of (as received) PLA pellets does not change the average molecular weight of the polymer.

Secondly, compounding dried neat PLA results in a decrease in both $M_{\mathrm{n}}$ and $M_{\mathrm{w}}$ values, without affecting the polydispersity index $\oslash$ or the molecular weight distribution (not shown here). The decreasing tendency of PLA molecular weight after compounding/granulation/drying stages is confirmed by the MFI evolution between dPLA (3.8 g/10 min) 


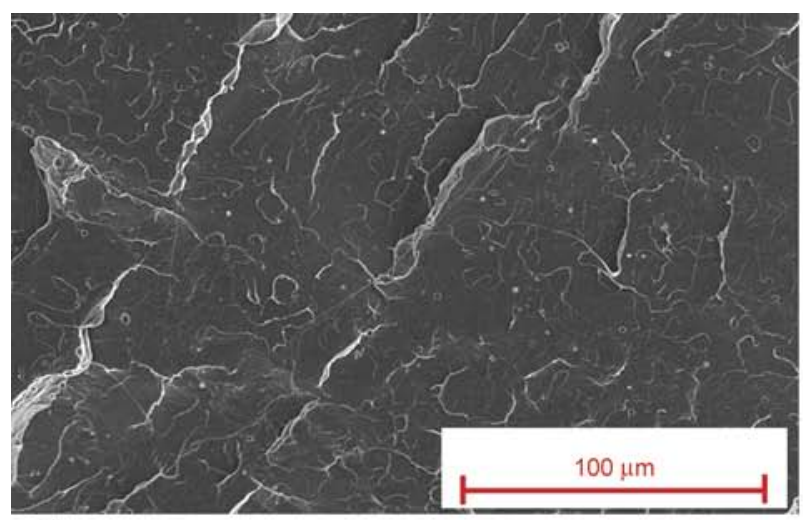

a)

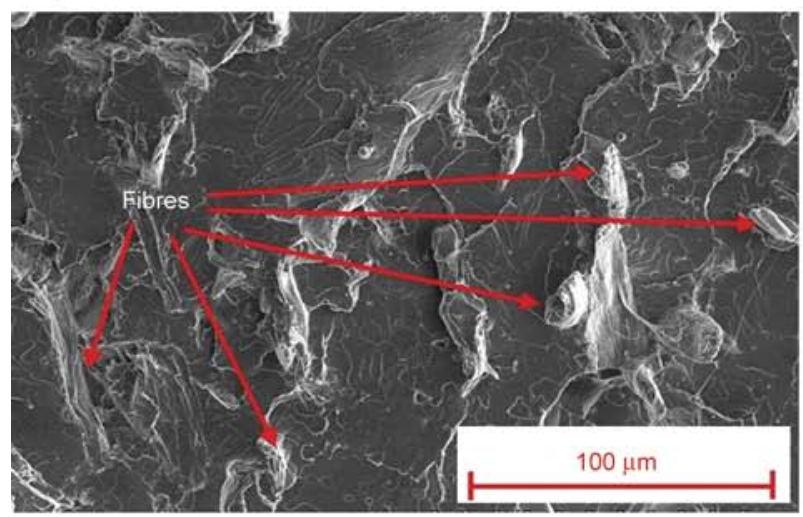

c)

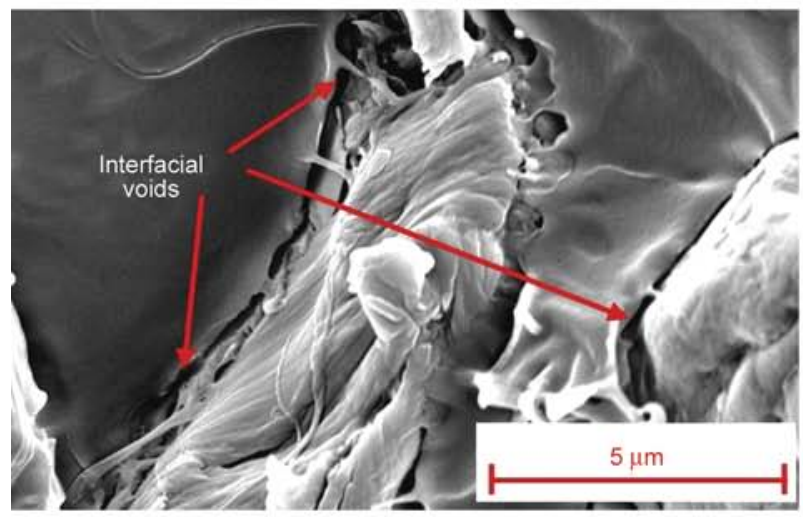

e)

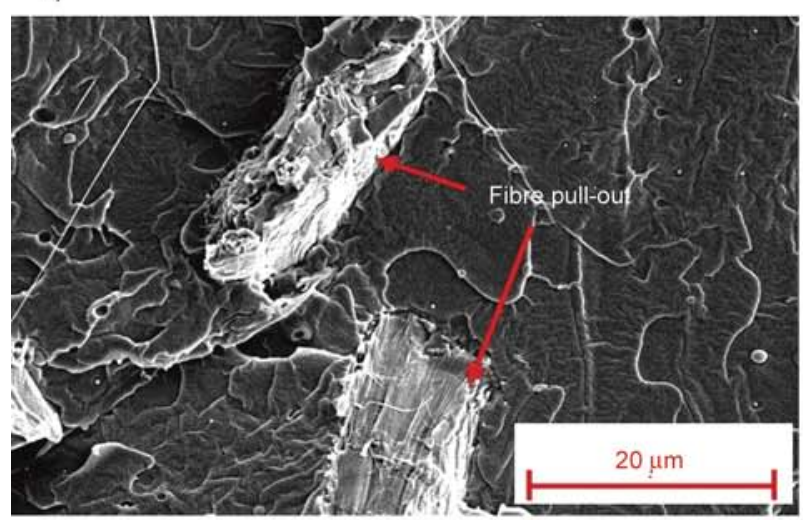

g)

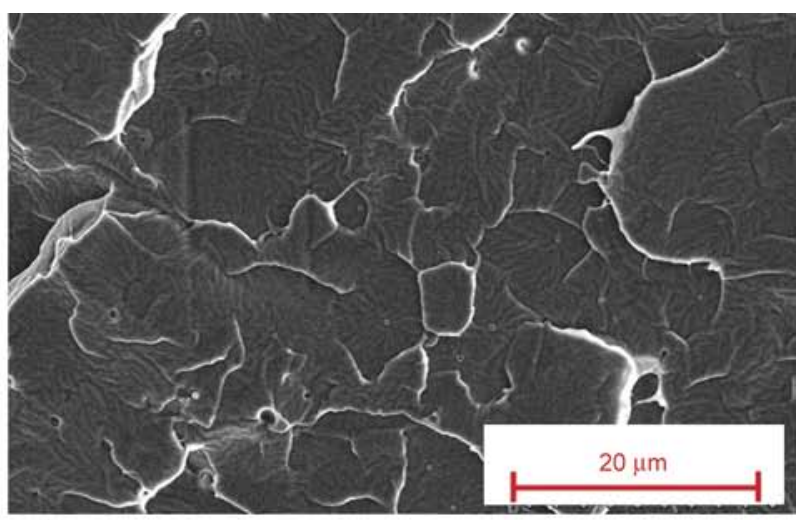

b)

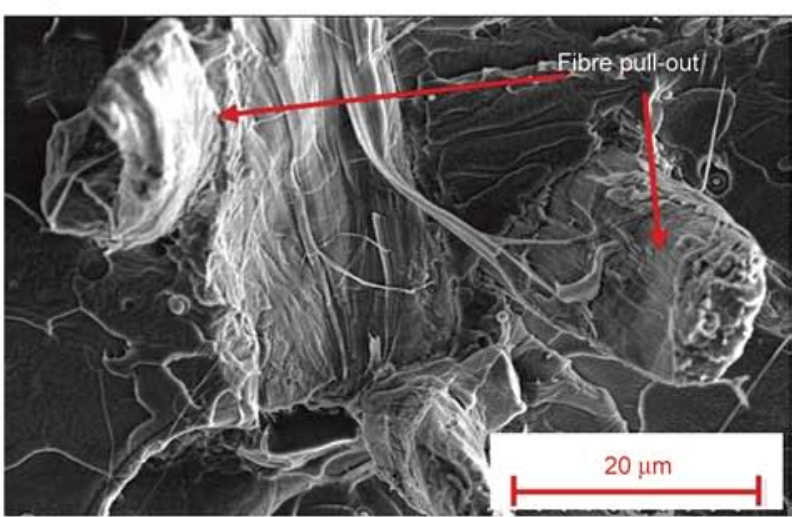

d)

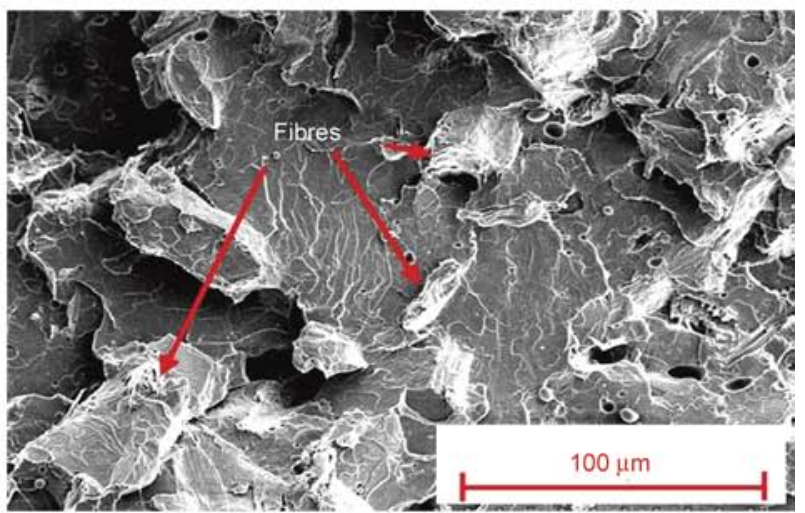

f)

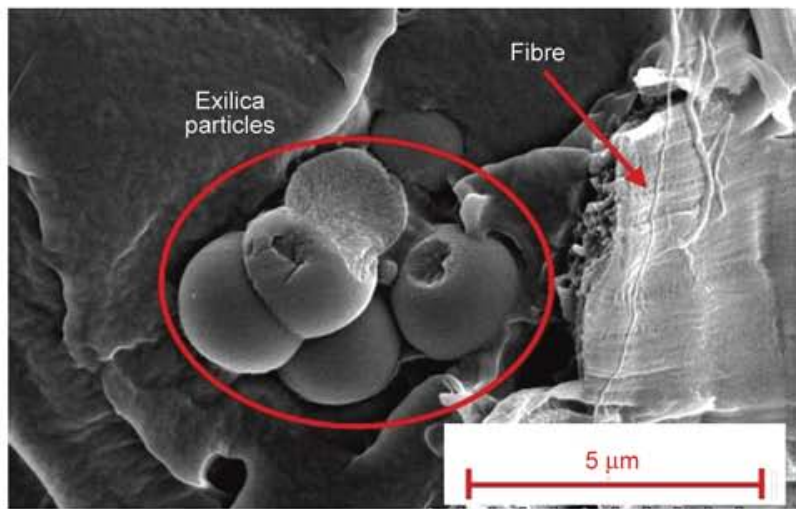

h)

Figure 3. SEM micrographs of the cryo-fractured surfaces of injection moulded neat PLA-CI (a, b), and PLA-biocomposites, without (PLA10F-CI, c, d, e) or with absorbent agent (PLA10F05Ex-CI, f, g, h)

and dPLA-C (5.8 g/10 min). These observations are in agreement with the results of Wang et al. [45], who found a decrease in the $M_{\mathrm{n}}$ of dried PLA, more or less important depending on the applied com- 
pounding temperature $\left(-4 \%\right.$ at $180^{\circ} \mathrm{C}$ and $-35 \%$ at $\left.200^{\circ} \mathrm{C}\right)$, for a same low screw speed $(100 \mathrm{rpm})$.

A more careful investigation of the molecular weight evolution before and after the passage through the twin-screw extruder, followed by cooling in a water bath and granulation, showed that these processing stages are responsible only for a part of PLA degradation $\left(M_{\mathrm{n}}:-7 \%, M_{\mathrm{w}}:-6 \%\right)$. In fact, an additional molecular weight loss $\left(M_{\mathrm{n}}:-10 \%, M_{\mathrm{w}}:-6 \%\right)$ occurs during the post-compounding drying step $(15 \mathrm{~h}$ at $45^{\circ} \mathrm{C}$, followed by $72 \mathrm{~h}$ at $80^{\circ} \mathrm{C}$, under vacuum), most probably caused by hydrolysis due to the high moisture contents (up to $0.6 \%$ ) acquired by the compounded materials during the cooling step in a water bath, at the exit of the extruder. It appears that this inevitable drying stage should be optimised, to limit the risk of further PLA hydrolysis at $80^{\circ} \mathrm{C}$.

The incorporation of $10 \mathrm{wt} \%$ of dried cellulose fibres into PLA causes a further decrease in $M_{\mathrm{n}}$ $(-7 \%)$ and $M_{\mathrm{W}}(-14 \%)$ values with respect to neat PLA after compounding, meaning that the PLA degradation is enhanced in presence of fibres. This further degradation of PLA when adding the filler is also confirmed by MFI (from 5.8 to $6.2 \mathrm{~g} / 10 \mathrm{~min}$ ), even if the expected increase in MFI due to PLA degradation is largely hidden by the presence of $10 \mathrm{wt} \%$ of cellulose fibres.

This evolution may be explained, on one hand, by the PLA hydrolysis in the presence of water molecules brought by the cellulose fibres. Indeed, the dried cellulose fibres, with $0.6 \mathrm{wt} \%$ residual water after the drying process, exhibit quite fast water uptake kinetics (about $2 \mathrm{wt} \%$ in $15-30 \mathrm{~min}$ ), which implies that even short-time manipulations of cellulose fibres during processing result in some water uptake. To limit the effect of this extra-water content brought into PLA matrix, the twin-screw extruder has a degassing zone placed after the mixing zone, and a vacuum pump is connected to extract water vapours. Nevertheless, the remaining humidity, once released inside the co-extruder, can generate some hydrolysis of PLA chains and so, a decrease in molecular weight. On the other hand, adding $10 \mathrm{wt} \%$ of cellulose fibres also induces an increase in melt viscosity, and so it generates higher shear stresses during the compounding process, which can result in thermo-mechanical degradation of PLA.

Finally, the injection moulding did not induce further significant degradation, as shown by the minor decrease in $M_{\mathrm{n}}$ and $M_{\mathrm{w}}$ values (less than 5\%, as com- pared to the compounded pellets). Same tendency is observed for the neat compounded PLA and the cellulose fibre/PLA biocomposites, with and without absorbent agent. These observations confirm the necessity to apply an effective post-compounding drying stage, for limiting the degradation during injection moulding process. This statement is also supported by comparing the results reported in this study with those of Carrasco et al. [46] and Pillin et al. [47], for injection moulding of virgin PLA pellets. In the first case, an important decrease of molecular weight $\left(M_{\mathrm{n}}:-30 \%, M_{\mathrm{w}}:-19 \%\right)$ was reported after the injection moulding of well-dried PLA2002D (ca. 4\% D-lactide, moisture close to zero), at a temperature profile of $180-200-210^{\circ} \mathrm{C}$. An injection moulding temperature higher than that used in the present study $\left(170-180^{\circ} \mathrm{C}\right)$ can justify more important polymer degradation. In the second case, Pillin et al. [47] reported a decrease in $M_{\mathrm{w}}$ of about $-17 \%$ during the injection moulding of PLA L9000 (ca. $8 \%$ D-lactide, and $0.5 \%$ residual moisture), at a temperature profile of $175-180-185-190^{\circ} \mathrm{C}$ close to the one used in the present study $\left(170-180^{\circ} \mathrm{C}\right)$. The important moisture content of PLA pellets used by Pillin et al. [47] would have favoured noticeable hydrolysis of polyester chains during injection moulding. These two comparisons confirm the important role of processing conditions, as well as residual moisture content and PLA stereochemistry, in the extent of polyester degradation during melt processing.

The presence of a low content of absorbent fine powder in PLA-biocomposite did not influence the molecular weight of PLA, which proves that, at least for low contents $(\leq 0.5 \mathrm{wt} \%)$, this absorbent agent neither prevents nor enhances the PLA degradation mechanism by chain scission.

\subsection{Thermal stability}

Figure 4a shows the influence of the different processing steps on the thermal stability of the neat PLA. The TGA/DTG thermograms are almost identical, for dried initial PLA pellets, compounded PLA pellets and injected PLA bars, and indicate a one-step decomposition process occurring within a narrow temperature range, $320-340^{\circ} \mathrm{C}$. The characteristic degradation temperatures at which 5, 50 and $95 \%$ of the total mass is volatilized $\left(T_{5 \%}, T_{50 \%}\right.$, and $\left.T_{95 \%}\right)$ and the temperature of the maximum rate of weight loss $\left(T_{\max }\right)$ are listed in Table 2. 
Table 2. Characteristic temperatures of thermal degradation of cellulose fibres, PLA and PLA-biocomposites

\begin{tabular}{|l|c|c|c|c|}
\hline \multicolumn{1}{|c|}{ Samples } & $\begin{array}{c}\mathbf{T}_{\mathbf{5} \%} \\
{\left[{ }^{\circ} \mathbf{C}\right]}\end{array}$ & $\begin{array}{c}\mathbf{T}_{\mathbf{5 0} \%} \\
{\left[{ }^{\circ} \mathbf{C}\right]}\end{array}$ & $\begin{array}{c}\mathbf{T}_{\mathbf{9 5}} \\
{\left[{ }^{\circ} \mathbf{C}\right]}\end{array}$ & $\begin{array}{c}\mathbf{T}_{\max } \\
{\left[{ }^{\circ} \mathbf{C}\right]}\end{array}$ \\
\hline dried Cellulose fibres & $264 \pm 2$ & $322 \pm 1$ & - & $323 \pm 1$ \\
\hline ndPLA & $319 \pm 2$ & $323 \pm 1$ & $327 \pm 1$ & $323 \pm 1$ \\
\hline dPLA & $321 \pm 2$ & $328 \pm 1$ & $337 \pm 3$ & $327 \pm 1$ \\
\hline dPLA-C & $323 \pm 1$ & $327 \pm 1$ & $336 \pm 1$ & $327 \pm 1$ \\
\hline PLA-CI & $321 \pm 1$ & $327 \pm 1$ & $333 \pm 1$ & $327 \pm 1$ \\
\hline dPLA10F-C & $316 \pm 1$ & $320 \pm 1$ & $351 \pm 4$ & $319 \pm 1$ \\
\hline PLA10F-CI & $314 \pm 1$ & $321 \pm 1$ & $349 \pm 2$ & $320 \pm 1$ \\
\hline dPLA10F05Ex-C & $313 \pm 3$ & $318 \pm 3$ & $359 \pm 4$ & $317 \pm 3$ \\
\hline PLA10F05Ex-CI & $315 \pm 1$ & $319 \pm 1$ & $365 \pm 1$ & $318 \pm 1$ \\
\hline
\end{tabular}

Mean \pm standard deviation

As shown by the thermograms, there is no noticeable influence of melt processing on well-dried PLA pellets. These results show that the thermal stability of PLA with $2 \%$ of D-units is not so sensitive to the small decrease in its molecular weight (up to $-14 \%$, as seen in the previous section).

A different trend was reported by Carrasco et al. [46] for PLA2002D after extrusion and injection moulding, i.e., a slightly shift of $T_{5 \%}$, more sensitive to the drop of molecular weight, as a result of processing. This difference might be due to the higher injection temperature used by Carrasco et al. [46], which induced a decrease in molecular weight of PLA.

Figure $4 \mathrm{~b}$ presents the TGA/DTG thermograms of cellulose fibres and PLA-biocomposites. Despite an effective first drying of the cellulose fibres, that decreased their moisture content from 7.5 to $0.6 \%$, the TGA curve indicates a first weight loss in the temperature range from $30-110^{\circ} \mathrm{C}$, which is most probably due to water evaporation. Indeed, as mentioned previously, the water uptake kinetics is rather fast (about $2 \mathrm{wt} \%$ in 15-30 min), and may explain at least in part, this first weight loss process. However, the main stage of weight loss of the cellulose fibres occurs between 180 and $410^{\circ} \mathrm{C}$, and corresponds to cellulose decomposition in volatile molecules such as carbon monoxide and dioxide, water, methane, ethane $[22,48]$.

The thermal degradation of PLA-based biocomposites occurs in one-stage process. The addition of cellulose fibres in PLA matrix mainly results in slight decrease in the onset decomposition temperature $\left(T_{5 \%}\right)$ from 321 to 316 and $314^{\circ} \mathrm{C}$ after compounding and compounding/injection moulding, respectively. A similar trend is noticed in $T_{50 \%}$, from 327 to $320^{\circ} \mathrm{C}$, after compounding, and with-
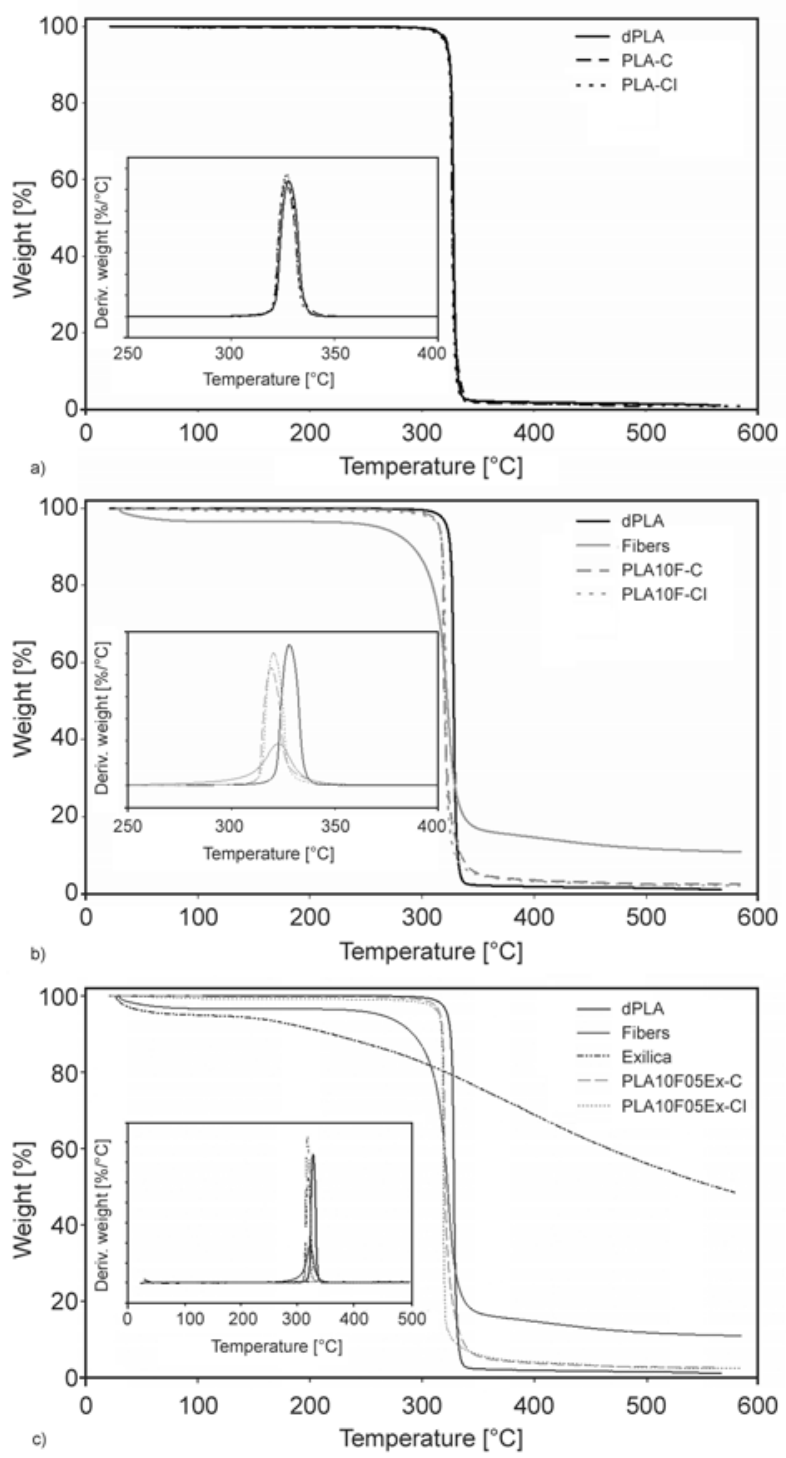

Figure 4. TGA/DTG thermograms of materials at different stages of processing: raw materials, pellets after compounding $/ 2^{\text {nd }}$ drying, and bars obtained by injection moulding: (a) processing of neat PLA; (b) preparation and processing of PLA10F biocomposite; (c) preparation and processing of PLA10F05Ex biocomposite

out any further significant changes after injection moulding. It is in agreement with the results reported by Pan and Inoue [55], which indicated a drop of $4^{\circ} \mathrm{C}$ of $T_{50 \%}$ with $10 \mathrm{wt} \%$ of kenaf in PLA, after compounding and injection moulding.

The addition of a low amount of absorbent agent $(0.5 \mathrm{wt} \%)$ in biocomposites does not affect in a significant manner the thermal stability of compounded biocomposite pellets (Figure 4c). Similarly, no effect of the injection moulding process is noticed for cellulose/PLA/absorbent agent system. 


\subsection{Thermal properties}

The thermal characteristics such as glass transition temperature $\left(T_{\mathrm{g}}\right)$, cold crystallization temperature $\left(T_{\mathrm{cc}}\right)$, crystallization enthalpy $\left(\Delta H_{\mathrm{cc}}\right)$, melting temperature $\left(T_{\mathrm{m}}\right)$, melting enthalpy $\left(\Delta H_{\mathrm{m}}\right)$ and crystallinity degree $\left(\chi_{\mathrm{c}}\right)$ obtained from DSC studies are summarized in Table 3. The PLA pellets, as received, show a $T_{\mathrm{g}}$ at $61.7^{\circ} \mathrm{C}$, a melting peak at $165.9^{\circ} \mathrm{C}$, without cold crystallization and a crystallinity degree of $46 \%$. The drying process of the pellets at $80^{\circ} \mathrm{C}$ for $22 \mathrm{~h}$ results in a broadening of glass transition and a slight increase of the $T_{\mathrm{g}}$ up to $64.0^{\circ} \mathrm{C}$, without modifying the melting temperature and crystallinity degree (Figure 5a). According to Magoń et al. [49] and Zuza et al. [50], this increase in the $T_{\mathrm{g}}$ value may be due to the confinement of the mobile amorphous phase fraction (MAF) [51, 52]. Indeed, a three phases model (mobile amorphous, rigid amorphous and crystalline phases) can be used to explain the glass transition dynamics. Contrary to the rigid amorphous phase fraction (RAF), which cannot contribute to the glass transition due to the partial trapping of the molecules in the crystalline lamellae, the MAF, sensitive to the constrains in the matrix, relaxes at the glass transition temperature. This phenomenon is observed in the present case for compounded PLA pellets (ndPLA-C) submitted to drying at $80^{\circ} \mathrm{C}$ for $72 \mathrm{~h}$. The second drying step acted as an isothermal cold crystallisation cycle [53], and the amorphous ndPLA-C pellets crystallised up to $37 \%$. The implicit confinement of the MAF results in a large broadening and shift of the $T_{\mathrm{g}}$, from about $54^{\circ} \mathrm{C}$ (for amorphous ndPLA-C pellets) to about $62^{\circ} \mathrm{C}$ (for semi crystalline dPLA-C pellets). These results are in agreement with data reported by Guinault et al. [54] for the crystallization of PLA $2002 \mathrm{D}$ at $85^{\circ} \mathrm{C}(4.3 \%$ of D-lactide).

As expected, the DSC analysis reveals that the PLA pellets obtained after compounding and granulation (ndPLA-C pellets) are mainly amorphous $\left(\chi_{\mathrm{c}} \leq\right.$ $3 \%$ ), due to the fast cooling stage in the water bath at $20^{\circ} \mathrm{C}$. The post-injection moulding cooling stage is short as well, and the slow crystallization kinetics of PLA at that temperature gradient does not allow the development of crystalline zones. Consequently, the crystallinity degree of PLA-CI bars is below $5 \%$, and the $T_{\mathrm{g}}$ around $55^{\circ} \mathrm{C}$. As shown in Figure 5a, the amorphous pellets of compounded PLA and the PLA bars present similar cold crystallization temperatures $\left(\approx 105^{\circ} \mathrm{C}\right)$. However, these two samples
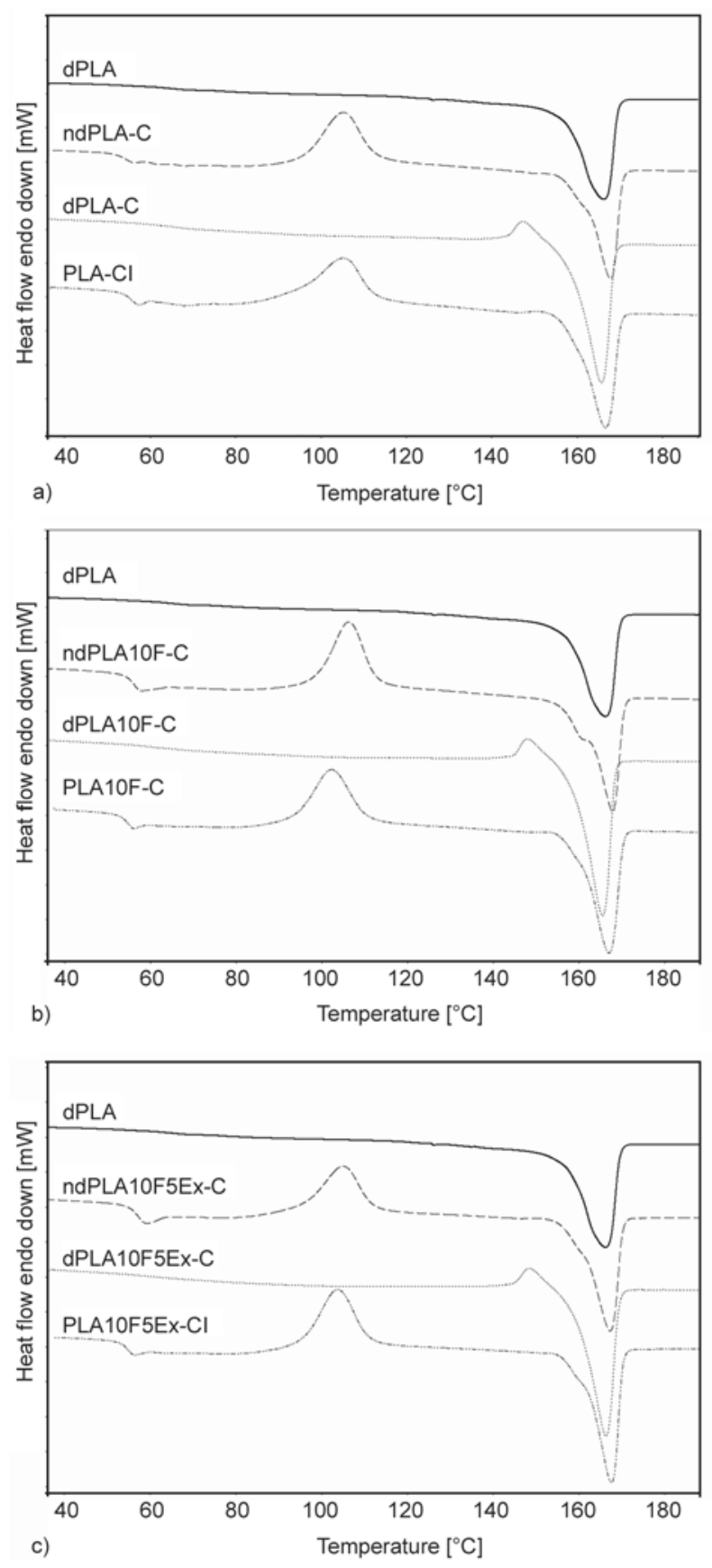

Figure 5. a) DSC thermograms of dPLA pellets, PLA-C pellets and PLA-CI bars, b) DSC thermograms of dPLA pellets, PLA10F-C pellets and PLA10F-CI bars. c) DSC thermograms of dPLA pellets, PLA10F05Ex-C pellets and PLA10F05Ex-CI bars

exhibit different melting behaviour: the ndPLA-C pellets resulted from compounding and granulation present a melting peak at $167.8^{\circ} \mathrm{C}$ with a shoulder $\left(160.9^{\circ} \mathrm{C}\right)$, whereas after injection moulding, the PLA-CI materials shows an exotherm at $150.4^{\circ} \mathrm{C}$, before the melting endotherm peak at $166.6^{\circ} \mathrm{C}$. As explained by Pan and Inoue [55], and also observed by Courgneau et al. [53], this exotherm prior to the 
Table 3. Thermal properties of PLA and PLA-biocomposites

\begin{tabular}{|c|c|c|c|c|c|c|}
\hline Samples & $\begin{array}{c}\mathbf{T}_{\mathbf{g}} \\
{\left[{ }^{\circ} \mathbf{C}\right]}\end{array}$ & $\begin{array}{c}\mathbf{T}_{\text {cc }} \\
{\left[{ }^{\circ} \mathbf{C}\right]}\end{array}$ & $\begin{array}{l}\Delta \mathbf{H}_{\text {cc }} \\
{[\mathbf{J} / \mathbf{g}]}\end{array}$ & $\begin{array}{c}\mathbf{T}_{\mathbf{m}} \\
{\left[{ }^{\circ} \mathbf{C}\right]}\end{array}$ & $\begin{array}{l}\Delta \mathbf{H}_{\mathbf{m}} \\
{[\mathbf{J} / \mathrm{g}]}\end{array}$ & $\begin{array}{c}\chi_{c} \\
{[\%]}\end{array}$ \\
\hline ndPLA & $61.7 \pm 1.5$ & - & - & $165.9 \pm 0.8$ & $41.9 \pm 1.4$ & $46 \pm 1$ \\
\hline dPLA & $64.0 \pm 0.2$ & - & - & $165.6 \pm 0.8$ & $42.5 \pm 0.8$ & $46 \pm 2$ \\
\hline ndPLA-C & $53.8 \pm 0.1$ & $105.2 \pm 0.1$ & $31.7 \pm 0.2$ & $\begin{array}{l}167.8 \pm 0.1 \\
160.9 \pm 0.1^{*}\end{array}$ & $34.0 \pm 0.9$ & $2 \pm 1$ \\
\hline dPLA-C & $62.4 \pm 1.3$ & - & - & $165.5 \pm 0.2$ & $39.4 \pm 0.3$ & $37 \pm 1$ \\
\hline PLA-CI & $55.0 \pm 0.3$ & $105.1 \pm 0.3$ & $31.4 \pm 0.7$ & $166.6 \pm 0.1$ & $34.5 \pm 0.5$ & $3 \pm 1$ \\
\hline ndPLA10F-C & $55.4 \pm 0.5$ & $106.3 \pm 0.1$ & $30.8 \pm 0.3$ & $\begin{array}{l}168.1 \pm 0.4 \\
161.1 \pm 0.2^{*}\end{array}$ & $36.4 \pm 0.1$ & $2 \pm 1$ \\
\hline dPLA10F-C & $62.4 \pm 0.8$ & - & - & $165.9 \pm 0.4$ & $31.4 \pm 0.3$ & $37 \pm 1$ \\
\hline PLA10F-CI & $53.8 \pm 0.1$ & $102.6 \pm 0.5$ & $29.6 \pm 0.5$ & $\begin{array}{l}167.2 \pm 0.2 \\
159.8 \pm 0.2^{*}\end{array}$ & $35.7 \pm 0.1$ & $4 \pm 1$ \\
\hline $\begin{array}{l}\text { ndPLA10F05Ex- } \\
\text { C }\end{array}$ & $55.9 \pm 0.1$ & $104.5 \pm 0.8$ & $29.0 \pm 0.3$ & $\begin{array}{l}167.4 \pm 0.2 \\
160.0 \pm 0.1^{*}\end{array}$ & $33.6 \pm 0.7$ & $3 \pm 1$ \\
\hline dPLA10F05Ex-C & $62.5 \pm 0.3$ & - & - & $166.0 \pm 0.4$ & $33.0 \pm 0.6$ & $37 \pm 1$ \\
\hline PLA10F05Ex-CI & $53.9 \pm 0.3$ & $103.4 \pm 0.6$ & $29.9 \pm 0.9$ & $\begin{array}{l}167.6 \pm 0.1 \\
159.9 \pm 0.7^{*}\end{array}$ & $33.1 \pm 0.4$ & $4 \pm 1$ \\
\hline
\end{tabular}

Mean \pm standard deviation

*shoulder of endotherm peak.

endotherm peak is due to the rearrangement of the instable crystalline form $\left(\alpha^{\prime}\right)$ of PLA into the stable crystalline form $(\alpha)$. The shoulder on the endotherm, already reported for neat PLA [33] and PLA/20 wt \% hemp [28], can be explained by three main mechanisms, namely melt-recrystallization, dual lamellae population [28], and dual crystal structure [33].

The DSC thermograms of biocomposites with or without absorbent agent (Figure $5 \mathrm{~b}$ and $5 \mathrm{c}$ ) are similar to those of neat PLA. The data related to these thermograms are summarised in Table 3.

As noticed for neat PLA, drying the biocomposites pellets after compounding (i.e., drying ndPLA10F-C and ndPLA10F05Ex-C pellets) increases their crystallinity degree up to $37 \%$, and probably induces the confinement of the mobile amorphous phase, as suggested by an increase in $T_{\mathrm{g}}$ and a broadening of the signal. The presence of cellulose fibres and $0.5 \mathrm{wt} \%$ fine absorbent microparticles in PLA generates a slight variation of $T_{\mathrm{cc}}$, without significant changes in melting temperatures values (Table 3 ).

\subsection{Mechanical properties of the biocomposites}

Figure 6 presents the stress-strain curves of neat PLA and PLA-biocomposites. It is clearly shown that the tensile properties of injection moulded PLA and PLA-based biocomposites are close. Neat PLA specimens fracture suddenly after the yield point, without observing neck, which indicates the brittle behaviour of PLA. The addition of cellulose fibres does not modify the brittle behaviour of PLA. The stresses at

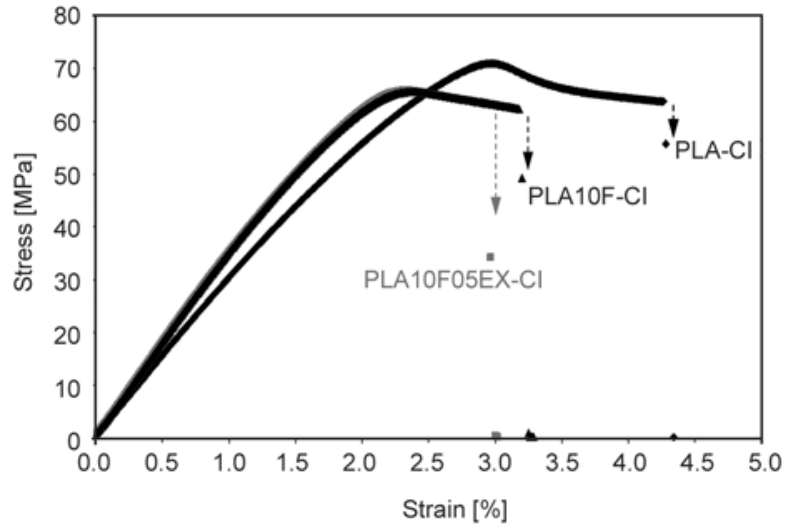

Figure 6. Stress-strain curves of neat PLA and PLA-based biocomposites

break remain similar, ca. $63 \mathrm{MPa}$, whereas a slight increase in Young modulus and a slight decrease in the elongation at break is noticed with the incorporation of $10 \mathrm{wt} \%$ of cellulose fibres. This trend is commonly observed with biocomposites PLA/natural fibres [43, 56, 57]. As shown in Table 5, at similar content of hemp fibres in PLA, Masirek et al. [28] noticed a decrease in the elongation at break $(-38 \%)$ and in the strength at yield $(-23 \%)$. The kenaf fibres/PLA-biocomposites also showed a drop of these mechanical characteristics [33]. This general feature is due to the poor adhesion between natural fibres and PLA, which was pointed out in Figure 3 , for the highly pure cellulose fibres. The existence of voids between the fibres and the PLA matrix prevents an effective stress transfer to the fibres, resulting in low strength values. Nevertheless, others factors may influence the mechanical proper- 
ties, including PLA intrinsic properties (stereochemistry, molecular weight) and microstructure (crystallinity, preferentially chain orientation...), as well as fibres characteristics (chemical composition, mechanical properties, size and aspect ratio), and finally, parameters related to the volume fraction of fibres and their orientation in biocomposites. Adding $8.4 \mathrm{vol} \%$ (10 wt $\%$ ) of highly pure cellulose fibres in PLA (Tables 4 and 5) increases the Young modulus (+18\%). Huda et al. [43] showed similar increase for PLA with $10 \mathrm{wt} \%$ of cellulose fibres from newspaper/magazine or kraft paper. A higher increase in rigidity, ca. $25 \%$, was found by Bax and Müssig [32] for PLLA with $10 \mathrm{wt} \%$ of flax fibres. Hence, the incorporation of fillers in polymer matrix increases its stiffness by restraining the chain movement and because of the high stiffness of cellulose [59].

The Charpy impact strength values of neat PLA and PLA-based biocomposite are reported in Table 4. Adding $10 \mathrm{wt} \%$ of cellulose fibres in PLA leads to a decrease in the impact strength from 24.1 to $17.3 \mathrm{~kJ} / \mathrm{m}^{2}(-28 \%)$. This Charpy impact strength drop may be due to the poor adhesion between fibres and matrix, which creates stress concentration. Hence, less energy is required to propagate cracks, initiated at the matrix/fibre interface or in high stress concentration regions. Similar decrease was noticed with $10 \mathrm{wt} \%$ of natural fibres (hemp, flax, ramie, cotton) in PLA (Table 5) [28, 32, 44]. Only the addition of synthetic cellulose fibres, Cordenka in PLA, by a completely different processing protocol based on pultrusion, granulation and injection moulding, showed a significant improvement $(+170 \%)$ of the Charpy impact strength. This may be explained by a worse adhesion between synthetic cellulose fibres and matrix than between natural fibres with PLA. Consequently, the higher number of debondings, pull-outs and fractures of Cordenka fibres will absorb more energy during impact than for the other natural fibres/PLA-biocomposites [32].

As previously shown with the morphology and thermal properties, adding $0.5 \mathrm{wt} \%$ of absorbent fine powder does not change the mechanical properties, neither the tensile nor the impact properties of the PLA-biocomposites with $10 \mathrm{wt} \%$ cellulose fibres.

Table 4. Mechanical characteristics of PLA and PLA-biocomposites bars

\begin{tabular}{|l|c|c|c|c|c|c|}
\hline \multicolumn{1}{|c|}{ Samples } & $\begin{array}{c}\chi_{\mathfrak{c}}{ }^{*} \\
{[\%]}\end{array}$ & $\begin{array}{c}\text { Charpy impact } \\
\text { strength } \\
{[\mathbf{J} / \mathbf{m}]}\end{array}$ & $\begin{array}{c}\text { Young's modulus } \\
{[\mathbf{M P a}]}\end{array}$ & $\begin{array}{c}\text { Tensile strength } \\
\text { at break } \\
{[\mathbf{M P a}]}\end{array}$ & $\begin{array}{c}\text { Tensile strength } \\
\text { at yield } \\
{[\mathbf{M P a}]}\end{array}$ & $\begin{array}{c}\text { Elongation at } \\
\text { break } \\
{[\%]}\end{array}$ \\
\hline PLA-CI & $3 \pm 1$ & $24.1 \pm 5.3$ & $3755 \pm 25$ & $63.1 \pm 2.9$ & $68.7 \pm 2.7$ & $4 \pm 1$ \\
\hline PLA10F-CI & $4 \pm 1$ & $17.3 \pm 2.2$ & $4426 \pm 58$ & $62.6 \pm 1.2$ & $65.4 \pm 0.8$ & $3 \pm 1$ \\
\hline PLA10F05Ex-CI & $4 \pm 1$ & $17.2 \pm 1.4$ & $4460 \pm 140$ & $62.1 \pm 2.0$ & $64.8 \pm 0.9$ & $3 \pm 1$ \\
\hline
\end{tabular}

${ }^{*}$ Crystallinity degree

Mean \pm standard deviation

Table 5. Mechanical properties of cellulose/PLA biocomposites and comparison with literature data for PLA-biocomposites with $10 \mathrm{wt} \%$ of natural fibres prepared according to different protocols. Values are relatives (in \%) compared to values of analogous neat PLA samples

\begin{tabular}{|c|c|c|c|c|c|c|}
\hline Fibre type & $\begin{array}{c}\text { Cellulose } \\
\text { content }^{*} \\
{[\mathbf{w t} \%]}\end{array}$ & \begin{tabular}{|c|} 
Charpy impact \\
strength \\
{$[\%]$}
\end{tabular} & $\begin{array}{c}\text { Young's } \\
\text { modulus } \\
{[\%]}\end{array}$ & $\begin{array}{c}\text { Tensile strength } \\
\text { at yield } \\
{[\%]}\end{array}$ & $\begin{array}{c}\text { Elongation at } \\
\text { break } \\
{[\%]}\end{array}$ & Reference \\
\hline Cellulose & 99.5 & 72 & 118 & 95 & 75 & This study \\
\hline Treated Hemp & $70-92$ & 50 & 102 & 77 & 62 & {$[28]$} \\
\hline Flax & $60-81$ & 62 & 125 & 95 & & [32] \\
\hline Flax & $60-81$ & $66^{* *}$ & & & & [44] \\
\hline Kenaf & $45-57$ & & 83 & 112 & 45 & [33] \\
\hline Ramie & $68-76$ & $75^{* *}$ & & & & [44] \\
\hline Cotton & $82-96$ & $77^{* *}$ & & & & [44] \\
\hline $\begin{array}{l}\text { Recycled cellulose } \\
\text { (from newsprint) }\end{array}$ & 75 minimum & $82^{\mathrm{a},{ }^{* *}}$ & 119 & 97 & & [43] \\
\hline Bamboo & $26-43$ & & 99 & 71 & 77 & [57] \\
\hline $\begin{array}{l}\text { Cordenka cellulose-based } \\
\text { manmade fiber }\end{array}$ & & 269 & 105 & 113 & & [32] \\
\hline
\end{tabular}

${ }^{a}$ Notched Izod

*adapted from [58]

** calculated by using information reported in figures. 
Similar trend was found with zeolites, pozzolan or white clay added to PLA/wood flour biocomposites to reduce the odour and VOCs emission [39]. Natural and synthetic zeolite have an average particle size over 7.7 and $9.7 \mu \mathrm{m}$, respectively, whereas pozzolan and white clay have one over $70 \mu \mathrm{m}$. Whatever the porous inorganic filler, at $3 \mathrm{wt} \%$, they did not affect the tensile strength of the biocomposite [39]. These observations are opposite to those reported by Yuzay et al. [60] for similar filler content added to neat PLA to remove or absorb offflavours and odours [61]. They found that $1 \%$ of zeolite, with an average particle size of $1-2 \mu \mathrm{m}$, did not modify the stiffness and the tensile strength whereas a higher content (3 or $5 \mathrm{wt} \%$ of zeolites) improves these mechanical characteristics of the material $(+20 \%)$. They attributed this behaviour to a good enough interfacial adhesion between zeolites and PLA matrix and dispersion of zeolites in PLA [60].

\subsection{Global odour analysis}

Table 6 presents the results of odour analysis during the different processing stages needed to obtain car interior parts. The testing conditions, i.e. heating at $90^{\circ} \mathrm{C}$ for $2 \mathrm{~h}$ in a confined atmosphere $(10 \mathrm{~g} / \mathrm{L})$, are based on typical testing requirements of OEM's, and are well adapted for simulating the most severe testing conditions for car interior applications. Results show that rating the global odour on a scale from 0 to 5, according to ISO 5496, is not sensitive enough to allow discrimination between samples. The same observation is noticed for the qualitative aspect of the odour: all the samples have common roasted and fatty odorous notes, except the cellulose that presents a unique fatty note.
At the opposite, dynamic olfactometry according to EN 13725 allows to demonstrate the impact of each processing step as well as the efficiency of the remediation agent.

The global odour concentration of dried raw materials (neat PLA pellets and cellulose fibres) is relatively low, of about $350 \mathrm{uo}_{\mathrm{E}} \cdot \mathrm{m}^{-3}$.

The compounding stage results in a large increase in odour concentration, for both neat PLA and cellulose fibres/PLA-biocomposites. The odour concentration of compounded PLA pellets (PLA-C) is doubled with respect to the initial dried pellets (dPLA). Furthermore, adding $10 w t \%$ of cellulose fibres in PLA matrix increases almost three times the odour concentration with respect to the initial dPLA pellets, despite the expected less odour-emissive nature of the chosen fibres. Indeed, as showed in Figure $4 b$ and $4 c$, the fibres (99.5\% of cellulose) do not significantly degrade in the temperature range used for the compounding stage $\left(170-180^{\circ} \mathrm{C}\right)$. Experimental investigations on the nature of the emitted VOCs (not reported here) indicate that this important increase is due to both the PLA degradation and the onset degradation $\left(264^{\circ} \mathrm{C}\right.$, Table 2$)$ of cellulose fibres, during the $6 \mathrm{~min}$ residence in the extruder at around $180^{\circ} \mathrm{C}$ and under high shear rate induced by the co-rotating twin-screws at $110 \mathrm{rpm}$. The effect of these degradations is not only a decrease in molecular weight of PLA (as shown in $\S 3.5)$, but also the formation and emission of volatile organic compounds (VOCs) with odour activity. The odorant notes emitted by processed neat PLA preconditioned for $2 \mathrm{~h}$ at $90 \mathrm{C}$ were described as roasted and fatty, whereas the dried cellulose fibres emitted mainly fatty notes.

Table 6. Odour analysis: cellulose fibres, PLA and PLA-biocomposites (after $2 \mathrm{~h}$ at $90^{\circ} \mathrm{C}$ )

\begin{tabular}{|c|c|c|c|c|c|}
\hline \multirow[b]{2}{*}{ Samples } & \multicolumn{2}{|c|}{$\begin{array}{l}\text { Olfactometric measurements according } \\
\text { to the European standard EN13725 }\end{array}$} & \multicolumn{3}{|c|}{$\begin{array}{l}\text { Odour analysis according to ISO } 5496 \\
\text { (Champs des odeurs }{ }^{\circledR} \text { methodology) }\end{array}$} \\
\hline & $\begin{array}{c}\text { Odour } \\
\text { concentration } \\
\left(\mathbf{u o}_{\mathrm{E}} \cdot \mathrm{m}^{-3}\right)\end{array}$ & $\begin{array}{c}\text { Sniffers } \\
\text { repeatability } \\
\left(\mathrm{uo}_{\mathrm{E}} \cdot \mathrm{m}^{-3}\right)\end{array}$ & Global note & $\begin{array}{l}\text { Confidence } \\
\text { Interval } \\
\text { (IC) }\end{array}$ & Odourous notes" \\
\hline dPLA & 355 & 55 & 2.6 & 0.2 & Roasted (2.2), fatty (1.1) \\
\hline dPLA-C & 780 & 0 & 3.0 & 0.0 & Roasted (2.4), fatty (1.6), rancid (0.9) \\
\hline PLA-CI & 625 & 130 & 2.7 & 0.2 & Roasted (1.9), fatty (1.6) \\
\hline Dried Cellulose fibres & 340 & 90 & 2.0 & 0.0 & Fatty (1.3) \\
\hline dPLA10F-C & 1025 & 80 & 2.6 & 0.3 & Roasted (2.3), fatty (1.6) \\
\hline PLA10F-CI & 1025 & 80 & 3.1 & 0.2 & Roasted (2.6), fatty (1.9) \\
\hline dPLA10F05Ex-C & 590 & 50 & 2.9 & 0.3 & Roasted (2.5), fatty (1.6) \\
\hline PLA10F05Ex-CI & 660 & 90 & 2.8 & 0.3 & Roasted (2.2), fatty (1.9) \\
\hline
\end{tabular}

${ }^{*}$ Quotation from 0 to 5: 0 - No perceptible odour; 5 - Outstanding odour on which the person's attention is focused 
Quite unexpectedly, the injection moulding stage does not generate any additional odour emission, neither for the neat PLA nor for PLA-biocomposites, despite some slight degradation observed for this processing stage.

However, the odour level generated by the final injection moulded parts based on PLA-biocomposites with $10 \mathrm{wt} \%$ cellulose fibres requires the use of a remediating agent, for instance a compound able to absorb VOCs and so to entrap them inside the biocomposite. Recently, Kim and coworkers [37-39] proposed adding porous inorganic fillers into polymer biocomposites, to adsorb odour and VOCs. They noticed a significant decrease of VOC concentration with $3 \%$ of pozzolan or natural and synthetic zeolites in PLA-biocomposites [39], without affecting negatively the thermal and mechanical properties. The efficiency of pozzolan on VOC emission was also showed at lower content, down to $0.5 \mathrm{wt} \%$, in the case of PP-based biocomposites [37]. Their second approach consisted in a bake-out process, by increasing the air temperature in an unoccupied but fully furnish car while maintaining some ventilation. The bake-out method applied to PLA-biocomposites $\left(70^{\circ} \mathrm{C}\right.$ for $\left.5 \mathrm{~h}\right)$ allowed reducing by more than $80 \%$ the total VOC emission factor. However, Kim et al. [38] did not consider the impact of such a treatment on PLA degradation and mechanical performances of PLA parts.

Our own results show the efficiency of a recent absorbent agent, i.e., micrometer sized solid spherical particles made of poly(1-methylpyrrol-2ylsquaraine), due to their internal amorphous porous network and small size. Indeed, adding only $0.5 \mathrm{wt} \%$ of this absorbent agent in PLA/cellulose fibres biocomposites is enough to divide by two the odour concentration of the compounded materials, as compared to the untreated biocomposites. As for the neat PLA and PLA-biocomposite, the injection moulding stage has no additional effect on the odour emission of the PLA-biocomposite with absorbent agent. The main odorant notes of the PLA-biocomposite with absorbent particles do not change, as compared with the untreated biocomposites.

\section{Conclusions}

Biocomposites parts made of PLA reinforced with $10 \mathrm{wt} \%$ of short pure cellulose fibres $(99.5 \%$ cellu- lose) were obtained via compounding and injection moulding. The biocomposites exhibited a well-dispersed morphology, but a generally weak adhesion PLA- cellulose fibre.

The incorporation of cellulose fibres in PLA, by compounding in a twin-screw extruder, induced a slight drop of molecular weight of PLA, due to the combined effect of shearing at high temperature and hydrolysis of PLA chains, highly sensitive to the small amount of moisture introduced by the (pre-dried) cellulose fibres. The compounding stage and the second drying cycle caused the main part of PLA degradation, as observed via molecular weight and MFI evolution, while the injection moulding stage had no significant impact.

A clear relation was shown between the increase of odour emission and the polymers degradation after compounding and post-compounding drying stages, for both neat (processed) PLA and PLA-biocomposites. The evolution of global odour concentration and odorant notes after each processing stage was investigated.

Finally, the global odour level of the biocomposite could be reduced by adding an organic absorbent agent (porous spherical beads). Its efficiency at only $0.5 \mathrm{wt} \%$ was proved via a decrease in the odour concentration by a factor 2 , without impairing the thermal and mechanical properties of the biocomposite. Further researches focusing on the nature of VOCs emitted by PLA-biocomposites are going on.

\section{Acknowledgements}

The authors would like to acknowledge INTERREG IV France - Wallonie-VLAANDEREN 2007-2013 (Project SENSOPLAST FW 1.1.2) and International Campus on Safety and Intermodality in Transportation (CISIT), Walloon Region (DGO6), Nord-Pas-de-Calais Region and European Community (FEDER) for financial support. Furthermore, the authors thank Annabelle Cingöz and Anne Borcy (CERTECH, Belgium) for the sensorial analysis, Adrian Boborodea for the SEC analysis (CERTECH, Belgium) and Aurélien Piroelle (Mines Douai, France) for his help in PLA physico-chemical and mechanical analysis.

\section{References}

[1] European Commission: Directive 2000/53/EC of the European parliament and the council of 18 Septembre 2000 on end-of-life vehicles. Official Journal of the European Communities (2000). 
[2] Rusu D., Boyer S. A. E., Lacrampe M. F., Krawczak P.: Bioplastics and vegetal fiber reinforced bioplastics for automotive applications. in 'Handbook of bioplastics and biocomposites engineering applications' (Ed.: Pilla S.), Wiley-Scrivener, Weinheim, 397-448 (2011). DOI: $10.1002 / 9781118203699 . \operatorname{ch} 15$

[3] Thouzeau C., Henneuse C., Sclavons M., Devaux J., Soulestin J., Stoclet G.: Emission of volatile organic compounds during processing and use of organoclaybased nanocomposites. Polymer Degradation and Stability, 98, 557-565 (2013).

DOI: $10.1016 /$ j.polymdegradstab.2012.11.019

[4] Kolstad J. J.: Crystallization kinetics of poly(L-lactide-co-meso-lactide). Journal of Applied Polymer Science, 62, 1079-1091 (1996).

DOI: $10.1002 /($ SICI) 1097-4628(19961114)62:7<1079 $\because$ AID-APP14>3.0.CO;2-1

[5] Kalia S., Avérous L., Domenek S., Courgneau C., Ducruet V.: Characteristics and applications of poly (lactide). in 'Biopolymers: Biomedical and environmental applications’ (Eds.: Kalia S., Avérous L.) Wiley, Weinheim, 183-224 (2011).

DOI: $10.1002 / 9781118164792 . c h 8$

[6] Ramy-Ratiarison R., Soulestin J., Lacrampe M. F., Krawczak P.: Peculiar crystallization behaviour of injection-molded PLA parts. in 'Proceedings of the $3^{\text {rd }}$ International Conference on Biodegradable and Biobased Polymers, BIOPOL 2011, Strasbourg, France' O-079 (2011).

[7] Julien J-M., Bénézet J-C., Lafranche E., Quantin J. C., Bergeret A., Lacrampe M. F., Krawczak P.: Development of poly(lactic acid) cellular materials: Physical and morphological characterizations. Polymer, 53, 5885-5895 (2012).

DOI: $10.1016 /$ j.polymer.2012.10.005

[8] Lim L-T., Auras R., Rubino M.: Processing technologies for poly(lactic acid). Progress in Polymer Science, 33, 820-852 (2008).

DOI: $10.1016 /$ j.progpolymsci.2008.05.004

[9] Tessier R., Lafranche E., Krawczak P.: Development of novel melt-compounded starch-grafted polypropylene/polypropylene-grafted maleic anhydride/organoclay ternary hybrids. Express Polymer Letters, 6, 937-952 (2012).

DOI: $10.3144 /$ expresspolymlett.2012.99

[10] Lafranche E., Krawczak P., Ciolczyk J-P., Maugey J.: Injection moulding of long glass fiber reinforced polyamide 66: Processing conditions/microstructure/flexural properties relationship. Advances in Polymer Technology, 24, 114-131 (2005).

DOI: $10.1002 / \mathrm{adv} .20035$

[11] Lafranche E., Krawczak P., Ciolczyk J. P., Maugey J.: Injection moulding of long glass fibre reinforced polyamide 6-6: Guidelines to improve flexural properties. Express Polymer Letters 1, 456-466 (2007). DOI: $10.3144 /$ expresspolymlett.2007.64
[12] Cilleruelo L., Lafranche E., Krawczak P., Pardo P., Lucas P.: Injection moulding of long glass fibre reinforced poly(ethylene terephtalate): Influence of carbon black and nucleating agents on impact properties. Express Polymer Letters, 6, 706-718 (2012). DOI: $10.3144 /$ expresspolymlett.2012.76

[13] Martins C. I., Lemos-Oliveira V. M., Lafranche E.: Processing, mechanical properties and morphology of injection moulding flax fibres reinforced polypropylene. in 'Proceedings of POLYCHAR 20, World Forum on Advanced Materials, Dubrovnik, Croatia', O 2-023 (2012).

[14] Kovács J. G., Soulestin J., Tábi T., Ramy-Ratiarison R., Lafranche E., Lacrampe M-F., Czigány T., Krawczak P.: Overall characterization of cellulose fiber reinforced PLA. in 'Proceedings of the $4^{\text {th }}$ ChinaEurope Symposium on Processing and Properties of Reinforced Polymers, Guilin, China' O-085 (2009).

[15] Soulestin J., Quiévy N., Sclavons M., Devaux J.: Polyolefins-biofibre composites: A new way for an industrial production. Polymer Engineering and Science, 47, 467-476 (2007).

DOI: $10.1002 /$ pen.20706

[16] Senthil Kumar K., Lafranche E., Lacrampe M. F., Krawczak P.: Injection moulding of flax fibre-reinforced polypropylene: Influence of processing conditions on tensile and impact strengths. in 'Proceedings of the $25^{\text {th }}$ Annual Meeting of the Polymer Processing Society, Symposium on Polymer Composites, Goa, India' GS-III:O7 (2009).

[17] Holbery J., Houston D.: Natural-fiber-reinforced polymer composites in automotive applications. Journal of the Minerals. Metals and Materials Society, 58, 80-86 (2006).

DOI: $10.1007 / \mathrm{s} 11837-006-0234-2$

[18] van Voorn B., Smit H. H. G., Sinke R. J., de Klerk B.: Natural fibre reinforced sheet moulding compound. Composites Part A: Applied Science and Manufacturing, 32, 1271-1279 (2001). DOI: $10.1016 / \mathrm{S} 1359-835 \mathrm{X}(01) 00085-9$

[19] Suddell B. C., Evans W. J.: Natural fiber composites in automotive applications. in 'Natural fibers, biopolymers and biocomposites' (Eds.: Mohanty A. K., Misra M., Drzal L. T.) CRC Press, Boca Raton, 237-266 (2005).

DOI: $10.1201 / 9780203508206 . c h 7$

[20] Summerscales J., Dissanayake N., Virk A, Hall W.: A review of bast fibres and their composites. Part 2 Composites. Composites Part A: Applied Science and Manufacturing, 41, 1336-1344 (2010). DOI: $10.1016 /$ j.compositesa.2010.05.020

[21] Bledzki A. K., Faruk O., Sperber V. E.: Cars from biofibres. Macromolecular Materials and Engineering, 291, 449-457 (2006).

DOI: $10.1002 /$ mame.200600113 
[22] Yang H., Yan R., Chen H., Lee D. H., Zheng C.: Characteristics of hemicellulose, cellulose and lignin pyrolysis. Fuel, 86, 1781-1788 (2007).

DOI: $10.1016 /$ j.fuel.2006.12.013

[23] Gassan J., Bledzki A. K.: Thermal degradation of flax and jute fibers. Journal of Applied Polymer Science, 82, 1417-1422 (2001).

DOI: $10.1002 /$ app.1979

[24] Ellison G. C., McNaught R., Eddleston E. P.: The use of natural fibres in nonwoven structures for applications as automotive component substrates. Ministry of Agriculture Fisheries and Food Agri-Industrial Materials, Research and development report (2000).

[25] Oksman K., Skrifvars M., Selin J-F.: Natural fibres as reinforcement in polylactic acid (PLA) composites. Composites Science and Technology, 63, 1317-1324 (2003).

DOI: 10.1016/S0266-3538(03)00103-9

[26] Bodros E., Pillin I., Montrelay N., Baley C.: Could biopolymers reinforced by randomly scattered flax fibre be used in structural applications? Composites Science and Technology, 67, 462-470 (2007). DOI: 10.1016/j.compscitech.2006.08.024

[27] Akil H. M., Omar M. F., Mazuki A. A. M., Safiee S., Ishak Z. A. M., Abu Bakar A.: Kenaf fiber reinforced composites: A review. Materials and Design, 32, 4107-4121 (2011). DOI: 10.1016/j.matdes.2011.04.008

[28] Masirek R., Kulinski Z., Chionna D., Piorkowska E., Pracella M.: Composites of poly(L-lactide) with hemp fibers: Morphology and thermal and mechanical properties. Journal of Applied Polymer Science, 105, 255268 (2007). DOI: 10.1002/app.26090

[29] Mathew A. P., Oksman K., Sain M.: The effect of morphology and chemical characteristics of cellulose reinforcements on the crystallinity of polylactic acid. Journal of Applied Polymer Science, 101, 300-310 (2006). DOI: $10.1002 /$ app.23346

[30] Gregorova A., Sedlarik V., Pastorek M., Jachandra H., Stelzer F.: Effect of compatibilizing agent on the properties of highly crystalline composites based on poly (lactic acid) and wood flour and/or mica. Journal of Polymers and the Environment, 19, 372-381 (2011). DOI: $10.1007 / \mathrm{s} 10924-011-0292-6$

[31] Graupner N., Herrmann A. S., Müssig J.: Natural and man-made cellulose fibre-reinforced poly(lactic acid) (PLA) composites: An overview about mechanical characteristics and application areas. Composites Part A: Applied Science and Manufacturing, 40, 810-821 (2009).

DOI: $10.1016 /$ j.compositesa.2009.04.003

[32] Bax B., Müssig J.: Impact and tensile properties of PLA/Cordenka and PLA/flax composites. Composites Science and Technology, 68, 1601-1607 (2008). DOI: $10.1016 /$ j.compscitech.2008.01.004
[33] Pan P., Zhu B., Kai W., Serizawa S., Iji M., Inoue Y.: Crystallization behavior and mechanical properties of bio-based green composites based on poly(L-lactide) and kenaf fiber. Journal of Applied Polymer Science, 105, 1511-1520 (2007).

DOI: 10.1002/app.26407

[34] Mathew A. P., Oksman K., Sain M.: Mechanical properties of biodegradable composites from poly lactic acid (PLA) and microcrystalline cellulose (MCC). Journal of Applied Polymer Science, 97, 2014-2025 (2005).

DOI: 10.1002/app.21779

[35] Cingoz A., Borcy A., Henneuse C., Piroelle A., Rusu D., Lacrampe M. F., Salazar R., Krawczak P., Ducruet V.: Odour and VOC emissions from PLA materials: Effect of processing. in ' 2 nd International Meeting on Material/Bioproduct Interaction, MATBIM 2012, Dijon, France' O-57 (2012).

[36] Cingoz A., Borcy A., Henneuse C., Piroelle A., Courgneau C., Lacrampe M. F., Salazar R., Krawczak P., Ducruet V.: Odour and VOC emissions from PLA materials: Food packaging and automotive applications. in 'Proceedings of the $10^{\text {th }}$ Edition ,Emissions and odours from materials", Bruxelles, Belgium' O 33 (2012).

[37] Kim H-S., Kim S., Kim H-J., Kim H-G.: Physicomechanical properties, odor and VOC emission of bioflour-filled poly(propylene) bio-composites with different volcanic pozzolan contents. Macromolecular Materials and Engineering, 291, 1255-1264 (2006). DOI: $10.1002 / \mathrm{mame} .200600212$

[38] Kim K-W., Lee B-H., Kim S., Kim H-J., Yun J-H., Yoo S-E., Sohn J. R.: Reduction of VOC emission from natural flours filled biodegradable bio-composites for automobile interior. Journal of Hazardous Materials, 187, 37-43 (2011).

DOI: $10.1016 /$ j.jhazmat.2010.07.075

[39] Kim H-S., Lee B-H., Kim H-J., Yang H-S.: Mechanical-thermal properties and VOC emissions of naturalflour-filled biodegradable polymer hybrid bio-composites. Journal of Polymers and the Environment, 19, 628-636 (2011).

DOI: $10.1007 / \mathrm{s} 10924-011-0313-5$

[40] Fischer E. W., Sterzel H. J., Wegner G.: Investigation of the structure of solution grown crystals of lactide copolymers by means of chemical reactions. KolloidZeitschrift und Zeitschrift für Polymere, 251, 980-990 (1973).

DOI: $10.1007 / \mathrm{BF} 01498927$

[41] Jaubert J. N., Tapiero C., Dore J. C.: The field of odors: Toward a universal language for odor relationships. Perfumer and Flavorist, 20, 1-16 (1995).

[42] Frone A. N., Berlioz S., Chailan J-F., Panaitescu D. M., Donescu D.: Cellulose fiber-reinforced polylactic acid. Polymer Composites, 32, 976-985 (2011). DOI: $10.1002 / p c .21116$ 
[43] Huda M. S., Mohanty A. K., Drzal L. T., Schut E., Misra M.: 'Green' composites from recycled cellulose and poly(lactic acid): Physico-mechanical and morphological properties evaluation. Journal of Materials Science, 40, 4221-4229 (2005).

DOI: $10.1007 / \mathrm{s} 10853-005-1998-4$

[44] van den Oever M. J. A., Beck B., Müssig J.: Agrofibre reinforced poly(lactic acid) composites: Effect of moisture on degradation and mechanical properties. Composites Part A: Applied Science and Manufacturing, 41, 1628-1635 (2010).

DOI: 10.1016/j.compositesa.2010.07.011

[45] Wang Y., Steinhoff B., Brinkmann C., Alig I.: In-line monitoring of the thermal degradation of poly(L-lactic acid) during melt extrusion by UV-vis spectroscopy. Polymer, 49, 1257-1265 (2008). DOI: $10.1016 /$ j.polymer.2008.01.010

[46] Carrasco F., Pagès P., Gámez-Pérez J., Santana O. O., Maspoch M. L.: Processing of poly(lactic acid): Characterization of chemical structure, thermal stability and mechanical properties. Polymer Degradation and Stability, 95, 116-125 (2010).

DOI: $10.1016 /$ j.polymdegradstab.2009.11.045

[47] Pillin I., Montrelay N., Bourmaud A., Grohens Y.: Effect of thermo-mechanical cycles on the physicochemical properties of poly(lactic acid). Polymer Degradation and Stability, 98, 321-328 (2008). DOI: $10.1016 /$ j.polymdegradstab.2007.12.005

[48] Jakab E., Mészáros E., Borsa J.: Effect of slight chemical modification on the pyrolysis behavior of cellulose fibers. Journal of Analytical and Applied Pyrolysis, 87, 117-123 (2010).

DOI: $10.1016 /$ j.jaap.2009.10.012

[49] Magoń A., Pyda M.: Study of crystalline and amorphous phases of biodegradable poly(lactic acid) by advanced thermal analysis. Polymer, 50, 3967-3973 (2009).

DOI: $10.1016 /$ j.polymer.2009.06.052

[50] Zuza E., Ugartemendia J. M., Lopez A., Meaurio E., Lejardi A., Sarasua J-R.: Glass transition behavior and dynamic fragility in polylactides containing mobile and rigid amorphous fractions. Polymer, 49, 44274432 (2008).

DOI: $10.1016 /$ j.polymer.2008.08.012

[51] Delpouve N., Saiter A., Dargent E.: Cooperativity length evolution during crystallization of poly(lactic acid). European Polymer Journal, 47, 2414-2423 (2011).

DOI: 10.1016/j.eurpolymj.2011.09.027
[52] Righetti M. C., Tombari E.: Crystalline, mobile amorphous and rigid amorphous fractions in poly(L-lactic acid) by TMDSC. Thermochimica Acta, 522, 118-127 (2011). DOI: $10.1016 /$ j.tca.2010.12.024

[53] Courgneau C., Domenek S., Lebossé R., Guinault A., Avérous L., Ducruet V.: Effect of crystallization on barrier properties of formulated polylactide. Polymer International, 61, 180-189 (2012).

DOI: $10.1002 /$ pi.3167

[54] Guinault A., Sollogoub C., Ducruet V., Domenek S.: Impact of crystallinity of poly(lactide) on helium and oxygen barrier properties. European Polymer Journal, 48, 779-788 (2012).

DOI: 10.1016/j.eurpolymj.2012.01.014

[55] Pan P., Inoue Y.: Polymorphism and isomorphism in biodegradable polyesters. Progress in Polymer Science, 34, 605-640 (2009).

DOI: $10.1016 /$ j.progpolymsci.2009.01.003

[56] De Rosa I. M., Iannoni A., Kenny J. M., Puglia D., Santulli C., Sarasini F., Terenzi A.: Poly(lactic acid)/ phormium tenax composites: Morphology and thermomechanical behavior. Polymer Composites, 32, 13621368 (2011). DOI: $10.1002 / p c .21159$

[57] Lee S-H., Wang S.: Biodegradable polymers/bamboo fiber biocomposite with bio-based coupling agent. Composites Part A: Applied Science and Manufacturing, 37, 80-91 (2006).

DOI: 10.1016/j.compositesa.2005.04.015

[58] Bismarck A., Mishra S., Lampke T.: Plant fibers as reinforcement for green composites. in. 'Natural fibers, biopolymers and biocomposites' (Eds.: Mohanty A. K., Misra M., Drzal L. T) CRC Press, Boca Raton, 37108 (2005).

[59] Qiu W., Zhang F., Endo T., Hirotsu T.: Preparation and characteristics of composites of high-crystalline cellulose with polypropylene: Effects of maleated polypropylene and cellulose content. Journal of Applied Polymer Science, 87, 337-345 (2003).

DOI: $10.1002 / a p p .11446$

[60] Yuzay I. E., Auras R., Selke S.: Poly(lactic acid) and zeolite composites prepared by melt processing: Morphological and physical-mechanical properties. Journal of Applied Polymer Science, 115, 2262-2270 (2010). DOI: $10.1002 / a p p .31322$

[61] Auras R., Selke S., Yuzay I. E.: Poly(lactic acid) and zeolite composites and method of manufacturing the same. U.S. Patent 20100236969 A1, USA (2010). 